\title{
The Post-hunter-gatherer Era Microbes Hypothesis for Chronic Inflammatory Diseases
}

\author{
Joyce Waterhouse ${ }^{1}$ \\ ${ }^{1}$ Affiliation not available
}

November 23, 2020

\begin{abstract}
This article proposes an extension of the hygiene hypothesis to explain chronic inflammatory diseases (CIDs) and their increase with westernization. Instead of emphasizing microbes that are missing/reduced due to westernization, a hypothesis is proposed that emphasizes the importance of microbes that are relatively novel. Environmental microbes encountered in association with a pre-agricultural lifestyle would presumably be the most coevolved with the human immune system and thus less likely to promote chronic disease. Post-hunter-gatherer era microbes (PHMs) are microbes that are encountered more frequently and/or at higher levels since humans ceased to live as nomadic hunter-gatherers. It is hypothesized that some PHMs, particularly those increasing with westernization, colonize human tissues and dysregulate/suppress the immune system. This hypothesized colonization of PHMs could cause allergy/hypersensitivity reactions leading to physiological stress, attacks on self-tissue, hypersensitivity reactions to similar cross-reacting environmental microbes and other allergens/antigens, greater vulnerability to diverse infections (e.g., COVID-19) and CIDs. Low-level colonization with diverse PHMs could explain high levels of comorbidities among CIDs, allergic responses to self-tissue (auto allergy), allergies to varied microbial taxa and allergen-initiated stress effects. Allergic reactions and the stress they cause might be adaptive by promoting expulsion and avoidance of potentially dangerous microbes. This is consistent with the observation that selective IgE deficiency leads to increased levels of diseases such as asthma, chronic rhinosinusitis, otitis media and autoimmune disease. PHMs that could be related to CIDs include microbes in tobacco smoke, increased Candida albicans and Aspergillus fumigatus that occurs in some situations, and increased exposure to Pseudomonas fluorescens and Yersinia spp. Additionally, fungi that tolerate multiple extreme environments have been found to be more likely to be opportunistic pathogens. This might suggest that microbes associated with human-created novel and extreme environments (e.g., antibiotics, xenobiotics) would have an increased ability to colonize and persist in humans. The PHM hypothesis could help explain contradictory findings on diet, why many chronic inflammatory diseases resemble chronic infections and why stress and xenobiotics are associated with CID incidence and exacerbations. Four foundations and 11 related hypotheses are discussed. Examples discussed include sarcoidosis, inflammatory bowel disease, asthma, long-term COVID-19 and Kawasaki disease.
\end{abstract}

\section{Introduction}

Chronic inflammatory diseases (CIDs), such as allergic and autoimmune diseases, include a wide array of diseases in which the immune system is thought to cause disease through excessive or dysregulated immune reactions. Since these diseases are only partly genetic[1], many environmental factors have been examined[2,3]. Environmental factors implicated include occupational/environmental chemical exposures[4], $\operatorname{diet}[3]$, infections[5-7] and stress[8,9].

Over the last 100 years, many of these CIDs have been increasing in Western countries, and recently have increased in association with westernization in developing countries[3,10,11] The term westernization, as used here, refers to the adoption of practices associated with Western culture that potentially impact health. The 
westernized diet typically includes increased consumption of animal products, fat (especially animal-derived fat and vegetable oils), sugar, ultra-processed foods/beverages, salt, and food additives. New exposures from xenobiotics/pollutants and pharmaceuticals are also included.

The hygiene hypothesis is one of the hypotheses proposed to explain the westernization-associated rise in chronic inflammatory disease[12]. The hygiene hypothesis originally attributed the allergic disease increase to decreasing rates of infections. These infections were proposed to "train" the immune system to not react to harmless allergens. Updates to the hygiene hypothesis have been proposed that focus on the reduction of microbes that humans were exposed to throughout evolutionary history[13-15]. These updates to the hygiene hypothesis will be referred to here as the altered microbiota hypothesis. In general, they propose that reduction in likely coevolved, often commensal, microbes lead to microbial and immune system imbalances that can give rise to chronic inflammatory diseases.

\section{The Post-hunter-gatherer Era Microbes (PHM) Hypothesis}

Although the reduction of some microbes is likely important, the PHM hypothesis focuses primarily on the increase in certain microbes, the post-hunter-gatherer era microbes, that might contribute to disease processes. In this section, the PHM hypothesis will be outlined, saving more detailed evaluation and supporting information for later sections.

Post-hunter-gatherer era microbes are microbes that are encountered more frequently and/or at higher levels since the advent of agriculture. Some PHMs are novel, such as mutated strains found in association with newer products/substances or relatively novel conditions. Other microbes are PHMs because human exposure to them has increased due to changing lifestyles (e.g., increases in microbes related to food storage or refrigeration). The third category, the "crowd/virulent" PHMs are the causes of infections that arose after agriculture and cause acute diseases in healthy individuals (e.g., smallpox). The last category will not be discussed further. Here the focus is on PHMs that typically have effects via colonization or less obvious infectious processes.

The microbial communities that humans have been exposed to have changed throughout the millennia as human activities have changed. PHMs were likely added with each advance (e.g., agriculture, the mining of metals). There were presumably selective pressures acting on human populations that led to some degree of toleration of the changing microbiotas. However, the PHM hypothesis proposes that in recent years the microbiota changes have occurred so rapidly that the newer PHMs have caused or contributed to the above-mentioned disease increases.

The human genetic makeup largely evolved during the more than 500 million years during which our ancestors lived as hunter-gatherers or gatherers. The microbial exposures associated with those lifestyles would presumably be the most conducive to optimal human functioning. The PHM hypothesis proposes that humans are increasingly exposed to a novel microbial environment[2]. A subset of these PHMs are proposed to colonize or infect human tissues leading to immune system dysregulation, allergy/hypersensitivity reactions, dysbiosis, chronic stress and CIDs.

Colonization and infection are terms that are used differently by different authors[16]. As used here, colonization will refer to a microbial strain's existence in some tissues at a low level that typically would not result in microbial abundances and host reactions that would be recognized as an infection. However, according to the PHM hypothesis, these colonizers can sometimes contribute to symptoms and disease processes.

The PHM hypothesis includes an important role for an extension of the toxin hypothesis of allergy. Rather than allergies being a mistake by the immune system, the toxin hypothesis proposes that allergy is an important defense mechanism that protects the host from harmful environmental substances, e.g., venoms and toxins[17,18]. More recent research continues to support this hypothesis[19,20]. It has also been extended to include allergic reactions serving to promote avoidance of certain microbes[21,22]. The PHM hypothesis proposes that the microbes that produce allergic reactions include numerous PHMs.

In addition to causing allergic symptoms, the PHM hypothesis proposes that PHM-associated allergens would 
also produce a stress response. Thus, the observed stress effects that occur in many CIDs could be at least partly due to stress responses resulting from PHMs and other sources of allergens. Chronic allergen-induced physiological stress could create and exacerbate psychological stress and lead to damaging stress-related and inflammation-related effects.

Cross-reactions play an important role in the PHM hypothesis. The effects of allergic reactions to PHMs would be magnified by cross-reactions with multiple allergens from other microbes, self-tissue or environmental substances. Also, one would expect cross-reactions between the PHMs that have colonized the human body and closely-related microbes in the environment.

Similar to what occurs in most infections, the PHM hypothesis proposes that the locations the microbes colonize largely determine the type and location of the symptoms. For instance, low abundance, hard-todetect PHMs colonizing the skin might lead to atopic dermatitis.

In addition, in many of these CIDs there is a waxing and waning of symptoms. A major contributor to symptom increases could be explained by increases in exposure to antigens in food and the environment that cross-react with the colonizing PHMs and thus increase inflammation.

There are many means by which immune dysregulation and/or suppression might occur as a result of PHM colonization. For instance, some PHMs might produce substances that dysregulate or suppress the immune system. Also, PHMs that colonize the human body could undergo antigenic changes that increase their survival and reproductive potential. These antigenic changes could also reduce the ability of the immune system to eliminate them. This might be partly because exposure to the cross-reacting environmental PHMs bias the immune system toward responding to the environmental PHMs' slightly different antigens. This could reduce the accuracy of the immune system's targeting of the PHMs that have already colonized the tissues. This might be seen as analogous to the situation that can occur in heterologous infections[23] when the immune response to one infecting microbial strain interferes with the response to another microbial strain. However, in this case, one of the strains is found in the environment and is encountered primarily in the mucosa.

Thus, the PHM hypothesis proposes that colonization or infection with a variety of PHMs could lead to various diseases that involve immune hypersensitivity reactions. These reactions may be directed against self-tissues, colonizing PHMs and cross-reacting environmental microbes/antigens that come into contact with the skin and mucosal surfaces. Stress responses and secondary infections often play a role in CID pathogenesis and are proposed to at least partly stem from PHM colonization. Varied genetic susceptibility factors would play a role in determining the type and severity of diseases that develops.

The PHM hypothesis proposes that CIDs might develop in the following way. PHMs from the environment colonize one or more tissues, sometimes after a higher-than-usual environmental exposure (e.g., through a skin or mucosal break and/or disruption). Acute infections, physical/psychological stressors and other factors might serve as additional triggers. Inflammation and barrier breakdown are among the changes that could result. In a proportion of cases, this could be followed by a vicious cycle of increasing PHM colonization, hypersensitivity reactions, increased physiological stress, increasing mucosal barrier breakdowns, secondary infections and tissue damage.

Susceptibility to acute infections that might result from PHM-induced immune dysregulation is part of the PHM hypothesis. The occurrence of repeated acute infections has been reported to be related to the onset or exacerbation of a number of CIDs[2,5,24].

One can postulate alternatives to this hypothesis that might also fit the overall framework presented here. One alternative involves a primary role for hunter-gatherer era microbes (non PHMs alternative). This alternative hypothesis seems less likely since humans would be presumably more adapted to tolerate such microbes and one would not expect the increase in chronic disease rates. However, it might be other factors related to westernization, like the loss of commensal microbes or the increase of xenobiotic exposures that account for a possible increase in susceptibility to non PHMs. 
Another alternative is that the implicated microbes do not actually colonize the tissues and instead are just present in the mucus or the gastrointestinal lumen (non colonization alternative). However, most of the other components of the PHM hypothesis might still be applicable to both these alternatives, and thus the overall hypothesis is still relevant. The situation likely varies among diseases and could even involve a mixture of microbes fitting the different alternatives just mentioned.

The idea that PHMs that might contribute to CIDs could be associated with at least some foods/beverages, pollutants and products associated with a westernized lifestyle might appear to be problematic. However, there is increasing recognition of the role of a westernized lifestyle in CIDs[3]. In addition, lifestyle interventions, such as dietary changes that improve disease outcomes and/or symptoms, are gaining support, as will be discussed later. If the PHM hypothesis is validated, a better understanding of the role of PHMs could lead to improvements in interventions, leading to more effective lifestyle and pharmaceutical approaches. Also, the negative effects of PHMs would generally only occur when a trigger occurs that causes the disease process to pass a certain threshold. Lifestyle and pharmaceutical approaches could reduce the PHMs or reduce the consequences of their presence.

\section{Foundations of the PHM hypothesis and comparison with other hy- potheses}

Four foundational ideas or observations are addressed briefly in this section. They are not novel, but it is proposed that they imply that the PHM hypothesis is a plausible explanation that might have been missed due to methodological limitations.

The first foundation is that a large proportion of species/strains remain uncharacterized. A low level of colonization, particularly in a limited area of the body, could easily be missed by current methods. The situation has been depicted as an iceberg, with the bulk of species/strains hidden from view[25]. This is in accord with ecological research that finds that in most ecosystems, there are many rare species[26,27], usually with patchy distributions[28]. And it is now recognized that differences between strains of species can be of crucial importance[29,30]. Thus, the relevant uncharacterized microbial diversity is likely very large.

The second foundation is that low abundance species or strains could be important. The low abundance oral bacteria Poryphoromonas gingivalis can produce a toxin that affects immune function and has been implicated in many diseases[31,32]. Hypersensitivity and cross-reactions are additional reasons that low abundance species/strains could be important. The additive effects of multiple colonizing species could also increase their effect.

The third foundation is that environmental microbes have the potential to be a significant component of the microbiota of humans[33]. Thus, environmental microbes might comprise a significant subset of the undetected rare species/strains likely present in humans.

The fourth foundation is that changing human activities have led to humans being exposed to many microbial species/strains that they would not have been exposed to at significant levels until recently. The selective pressures from extreme conditions that human activities create for microbes (e.g., cleaning solutions, antimicrobials, toxic chemicals, food processing procedures, industrial pollution) could lead to an increase in novel microbial taxa. These novel microbes would often tolerate diverse and extreme conditions, which might include conditions present in the human body. For instance, it has been found that fungi that tolerate multiple types of extreme environments (polyextremotolerant) are more likely to be opportunistic pathogens[34].

Thus, these foundational ideas and findings in microbiology and ecology suggest that there are far more novel PHMs inhabiting the human body than has been recognized. They support the plausibility of the hypothesis that relatively low virulence, low abundance PHMs might play a significant role in CIDs.

Part of the usefulness of the PHM hypothesis is that it brings together multiple hypotheses and observations 
in a way that could explain common features of many CIDs. Some of the similarities and differences between the PHM hypothesis and 11 related categories of hypotheses follow.

1. The hygiene hypothesis[12] and altered microbiota hypothesis[13-15] focus on the absence/reduction of microbes as the cause of microbiota imbalances leading to disease. Although sharing the emphasis on changes in microbial communities, the PHM hypothesis focuses on microbes that are increased in association with a post-hunter-gatherer lifestyle.

2. The molecular mimicry hypothesis posits a cross-reaction between an infectious agent and self-tissue as a cause of autoimmune disease. Root-Bernstein et al[35] discusses this hypothesis and suggests that the need for multiple exposures to pathogens or environmental factors could explain why frequent microbial cross-reactions with self-tissue only occasionally lead to autoimmune disease. The PHM hypothesis also includes a role for molecular mimicry and the likely involvement of multiple disease agents. In the PHM hypothesis, PHMs and opportunistic pathogens that take advantage of an immune system dysregulated by PHMs are implicated.

3 . The xenobiotic causation hypothesis[4] focuses on the role of pollution and novel environmental substances in causing CIDs. The PHM hypothesis proposes that xenobiotic-associated PHMs that colonize an affected organ or tissue could be the primary trigger for disease in at least some cases. Alternatively, one or more PHMs may exacerbate the effects of the xenobiotic.

4. The macronutrient emphasis of microbiome research focuses on high sugar, high fat and low fiber diet effects on the microbiome[3]. Changes in levels of these macronutrients leading to changes in immune function, dysbiosis, intestinal permeability and microbial translocation are being observed[36,37]. The PHM hypothesis includes the macronutrient role, but emphasizes how macronutrients might affect the abundance of PHMs. The PHM hypothesis also posits that low abundance PHMs in certain foods/beverages and inhalants contribute to and may initiate inflammation and the resulting dysbiosis and intestinal permeability.

5. The toxin hypothesis of allergy proposes that allergic reactions occur as a defensive response against toxins in the environment $[17,18]$. The PHM hypothesis includes this view of allergy but also includes PHMs as instigators of defensive allergic reactions and proposes an important role for PHM colonization of human tissues.

6. Psychological stress has been proposed to play an important role in the development and exacerbation of CIDs[9,38], and the PHM hypothesis includes this. However, allergy/hypersensitivity to microbes and other allergens is seen as a crucial and generally overlooked source of physiological stress that can initiate or exacerbate psychological stress.

7. Hypotheses regarding chronic infection as a cause of CIDs, such as asthma, chronic rhinosinusitis, inflammatory bowel disease and some autoimmune diseases have been proposed[2,39,40]. The PHM hypothesis posits that low abundance PHMs are often the cause of immune dysregulation and/or suppression leading to the more overt opportunistic pathogens' increase. The observed opportunistic pathogens may or may not be PHMs as well.

8. Infection by a microbe that also involves hypersensitivity to that microbe is not new (e.g., allergic bronchopulmonary aspergillosis, severe asthma with fungal sensitization). The PHM hypothesis proposes that this concept is applicable to many CIDs, but low levels of the microbes involved are limiting their detection.

9. Focal infection theory proposed that infection in one part of the body is sometimes related to chronic disease processes in another part of the body. The earlier view was that bacterial allergy was often involved in symptom causation[2]. The PHM hypothesis is similar; however, it also proposes that the microbes that are the underlying cause are related to the post-hunter-gatherer lifestyle, and that allergy-related stress, cross-reactions with self-tissues and inhaled/ingested antigens are often involved.

10. Daschner[22] proposed an evolution-based hypothesis for symptoms related to fungi in damp buildings, viewing symptoms as a means of causing avoidance of infection with fungi. The PHM hypothesis is similar but broader, including non-fungal microbes as well as other components, such as a primary role for microbial colonization and relatively novel species/strains.

11. A role for novel microbial exposures has been proposed in some hypotheses. The cold chain hypothesis 
links Crohn's disease to microbes that survive well in refrigerated food[6,41]. The PHM hypothesis includes this hypothesis in that consumption of refrigerated food that likely contains PHMs would be a part of a post-hunter-gatherer lifestyle. Other hypotheses that implicate human microbiota effects from novel sources of microbes[42,43], xenobiotics[42] and westernization-related variants of the normal microbiota[44] also have some features in common with the PHM hypothesis.

To summarize, the PHM hypothesis builds upon previous observations, ideas and hypotheses. The hypothesis is consistent with much published data, makes predictions that are testable, and could potentially lead to clinical advances.

\section{Evaluation of the PHM hypothesis}

This section includes a more in-depth examination of the components of the PHM hypothesis. In addition, supportive findings, illustrative examples, diet, the built environment, xenobiotics and immunosuppressive medications will be discussed. The section ends with an assessment of the potential relevance of PHMs to diseases, such as coronavirus disease 2019 (COVID-19), as well as post-infectious syndromes.

\section{Post-hunter-gatherer era microbes}

Ever improving methods in recent decades are allowing increasingly subtle and delayed effects of microbes to be studied. Tissues of the human body that were thought to be sterile in healthy individuals have been reported to contain microbial communities. Examples include microbiotas found in the blood[45-47], lungs[48], synovial fluid[49] and possibly even the brain[50-54]. In addition, there are likely other microbes that are too low in abundance to be detected using current methods[25]. Although some researchers attribute these findings to laboratory contamination, other researchers describe the careful use of controls and the differences founds in microbial communities between controls and patients[55].

Man-made or processed products and toxic chemicals do not seem conducive to significant levels of microbial survival; however, the adaptability of some microbes has now been demonstrated in numerous extreme environments. It may be that the only sterile places on earth are a few laboratory cleanrooms, some hot springs, volcanoes and areas over 150 degrees Centigrade deep in the earth[56]. Scientists at NASA have found new microbial species in their cleanrooms[57]. Some bacterial strains have even been found to use cleaning products as their fuel source[58].

As discussed above, the PHM hypothesis proposes that a subset of low abundance PHMs are important in human disease. The ability of some environmental PHMs to colonize or infect animals could be enhanced by dual use virulence[59]. This occurs when microbes have evolved means to survive inside of their single-celled predators and this allows them to survive inside human cells.

It has been suggested that virulence in animals is of questionable value to many microbes[60]. Thus, low virulence microbes may be common. A number of examples of potentially low virulence environmental PHMs are discussed below.

Some examples of PHMs have been found in high salt conditions. For example, halophilic Archaea[61,62] and bacteria[62] have been found in table salt and in the human digestive tract. Fungi from the genus Wallemia are found in salt-preserved fish[63]. Human exposure to such halophilic microbes was likely low before salt preservation.

The probable PHM, Mycobacterium immunogenum, found in metalworking fluid, caused hypersensitivity pneumonitis in some machinists[64]. The PHM hypothesis suggests that there may be some degree of colonization of this species in the lungs of the affected workers.

Tobacco smoke has been found to be a rich source of microbes, including potential pathogens, and further research is needed to determine their role in diseases like chronic obstructive pulmonary disease (COPD)[65]. 
Even smoke from wildfires[66,67] has viable microbes, and their effects need more study.

Researchers are beginning to look at the pathogenic potential of air pollution associated microbes. Particulate matter that is 2.5 um or less is a source of microbes that could lead to pathological effects[68,69]. A study found that the proportion of pathogenic species in air samples increased with air pollution levels associated with urbanization[70]. Detection of 142 new microbial genera in the pharynx followed a severe air pollution event[71].

A review of indoor environments associated with water highlights the many relatively novel and extreme conditions that microbes are exposed to in buildings[34]. As mentioned above, recent work has found that fungal taxa that tolerate multiple extreme environments tend to include more opportunistic pathogens[34].

Many extreme conditions, such as high temperatures, dry conditions, and cleaning products found in the built environment would prevent survival of many microbes. However, other microbes that tolerate extremes would likely increase under the high selection pressure of the extreme conditions. The human immune system response to microbes often creates another extreme environment (e.g., production of oxidants). Thus, microbes' evolved toleration of extreme environmental conditions may be advantageous for their survival within humans.

Research shows that dishwashers are inhabited by a polyextremotolerant type of black yeast that is an opportunistic pathogen[34]. In addition, a greater level of allergy in households that use dishwashers compared to those that use traditional hand dishwashing was found[72]. More microbes surviving the hand dishwashing has been suggested to be responsible for the lower rate of allergy. This is in accord with the altered microbiota hypothesis, which proposes that greater microbial diversity is protective.

Alternatively, the PHM hypothesis might suggest that dishwashers typically contain more polyextremotolerant microbes that are capable of colonizing humans, and that could increase allergy. Polyextremotolerant PHMs from the dishwasher might colonize human tissues and lead to allergic reactions. However, it should be noted that the difference in allergic disease was not large, and there are many possible confounding factors, so it would be premature to make conclusions with regard to dishwasher use[73].

In general, a problem with these types of observational studies is that there is confounding between lowering the total microbial levels and increasing overall microbial polyextremotolerance. Cleaning and other factors that reduce total microbial levels create more challenging and extreme conditions for microbes, likely selecting for the more polyextremotolerant taxa.

Thus, other types of studies will be needed to distinguish the effect of the cleaning-related reduction of microbial diversity from the increase in polyextremotolerant PHMs that could occur. In any case, the two explanations are not mutually exclusive. The lower diversity could be a cofactor that increases polyextremotolerant PHMs' ability to survive in the environment and/or colonize humans.

The distribution patterns of PHMs are not likely to be simple. Even without extensive cleaning, including in natural environments, PHMs that could colonize humans and contribute to disease could be present. For instance, PHMs might be in the soil, as a result of factors that introduce or select for PHMs, such as air and water pollution.

Another example of the potential role of PHMs is related to the association between bacterial virulence and antibiotic resistance[74]. Antibiotics are another factor that create an extreme environment that microbes are selected to tolerate. Thus, antibiotics might increase the numbers of pathogenic polyextremotolerant microbes able to colonize/infect the human body. The highly virulent antibiotic resistant microbes are known. However, antibiotic use may also result in other, lower abundance PHMs, with more subtle effects. An example is the cell wall deficient forms that are created under adverse conditions, such as certain antibiotics[40,75-77].

The PHM hypothesis takes the perspective that microbiota changes have been occurring for thousands of years alongside human cultural changes. The most significant changes likely occurred when populations 
began forming more permanent settlements and food processing was adopted[2]. In the following centuries, agriculture, large settlements and mining of metals presumably began changing microbial exposures even more. For instance, food storage would lead to increases in some food-associated microbes (e.g., fungi causing ergotism). However, the PHM hypothesis proposes that the known microbes contributing to disease are only the most easily detected, and there are many more awaiting discovery and characterization.

Thus, the PHM hypothesis is able to explain why many of these CIDs were present at a low level before the modern, more hygienic, antibiotic era[78-80]. The earlier presence of these diseases could have resulted from changing PHM exposures in the post-hunter-gatherer era.

\section{Allergy, hypersensitivity and stress}

The toxin hypothesis of allergy is related to the PHM hypothesis and the stress response. As mentioned previously, the toxin hypothesis proposes that allergy is an important defense mechanism that protects the host from harmful environmental substances, e.g., toxins, irritants, and venoms[17,18].

Palm et al[18] describe how the high sensitivity of IgE-mediated responses may have evolved to allow anticipation of dangerous exposures and thus cause avoidance of noxious substances. Experiments in mice and rats sensitized to a specific food allergen produced stress/anxiety effects and avoidance behavior associated with trace amounts of that specific allergen in their cages[81-83]. The anxiety-like behavior was shown to be dependent on allergic mechanisms. Corticotropin releasing hormone and Th2 cytokine increases in the prefrontal cortex paralleled the allergen-induced anxiety in the rat experiments[82]. It seems plausible that these allergy-induced effects also occur in humans. Observational studies show stress-related neuropsychiatric disorders are associated with allergic disorders in humans[84,85]. Although the above findings were related to IgE-mediated hypersensitivity, it may be that other types of immune hypersensitivity would have a similar relationship to stress responses.

Stress effects (e.g., increased anxiety, sleep disruption, elevated heart rate, and lower heart rate variability) occur in many CIDs $[2,9,86,87]$. The PHM hypothesis proposes that this is largely caused by frequent stress responses from exposures to PHM antigens and other cross-reacting antigens/allergens due to PHM colonization. This underlying physiological stress from PHM colonization could lead to greater perceived stress effects from ordinary daily activities and adverse life events.

Chronic stress can have significant effects on immune function through many mechanisms [88,89], including changes in the gut microbiota[90] and reduced secretory IgA[91,92]. A microbe-driven COPD-like disorder spontaneously developed in aging mice with SIgA deficiency[93].

IgE responses may be protective against diverse pathogens. For instance, studies have provided evidence that anti-microbial IgE antibodies may play a protective role in HIV[94] and Borrelia burgdorferi [95] infections. The association of selective IgE deficiency with increased asthma, chronic rhinosinusitis, otitis media, autoimmune disease, cardiovascular disease and cancer may be relevant[96-99]. Although the significance of these associations is uncertain, they are compatible with the view that $\operatorname{IgE}$ antibodies help protect humans from harmful colonization/infection.

PHM colonization could signal the immune system that there is a need for an increased protective response, including allergic responses and avoidance behavior. Thus, allergic symptoms and stress responses that would increase avoidance would be appropriate.'

More research is needed, but these findings are compatible with microbial hypersensitivity contributing to the defense against many types of microbes, including PHMs.

\section{Cross-reactions}

Cross-reactions play an important role in the PHM hypothesis. Trost et al[100] found that "no human protein is exempt from bacterial motifs." The extensive cross-reactivity they found between only 40 bacterial species 
and human self-tissue is significant. It also may have implications for agricultural products. It seems plausible that the plant-associated microbiota would have a similar high level of cross-reactivity with plant proteins. The PHM hypothesis proposes that food hypersensitivity might be at least partly related to plant-associated microbial antigens cross-reacting with known food allergens.

Plant microbes that increase after harvest and reach elevated levels in stored food might be a source of PHMs that colonize humans. PHMs would also likely be present in animal products, due to the animals' microbiotas including PHMs they acquired from their food and other sources. Cooking eliminates most of the microbes but is likely insufficient to eliminate all PHMs.

Cross-reactions are a potentially significant factor in CIDs as suggested by two recent examples. Bacher et al[101] provided evidence that a cross-reaction between two fungi, intestinal C. albicans and lung A. fumigatus, could lead to the inflammatory lung disease, allergic bronchopulmonary aspergillosis. Both fungi might be considered to be PHMs. High A. fumigatus exposures can occur in farming[102] or in damp or water-damaged buildings[103,104]. C. albicans overgrowth might be related to westernization-associated factors, such as diet[105] and medication[106].

Another example is a study[107] that found that Pseudomonas fluorescens cross-reacts with gliadin and might be linked to celiac disease. P. fluorescens can survive in refrigerated food and is found in moldy buildings, on walls and shower fixtures[108] and thus might be a PHM.

\section{Chronic inflammatory disease features}

Many characteristics of CIDs are consistent with the PHM hypothesis. Given the diversity of exposures, the PHM hypothesis suggests that PHMs are numerous and each patient has a unique mix of PHMs colonizing varied tissues. Consequently, comorbidities among CIDs would be expected to be common and allergic, autoimmune and other inflammation-related diseases would have significant overlap. And this is increasingly being found.

Allergy is being found in autoimmune and other CIDs. For example, in a large retrospective analysis of a UK population, Krishna et al[109] found a significantly higher rate of at least one of 3 allergic diseases (allergic rhinoconjunctivitis, atopic eczema and asthma) in almost all of the 11 CIDs that they examined. Allergic disorders or sensitization have been found to be associated with Type 1 diabetes[110-112] and with diabetes associated autoantibodies[113]. A recent analysis indicated that celiac disease and HLA-related autoimmune disease susceptibility was associated with IgE sensitization in young children[114].

Autoantibodies are common and occur even in people who are healthy[115,116]. It has been proposed that autoantibodies might only become a problem when there is a source of chronic immune activation, e.g. from chronic infection, causing a higher level of autoimmunity than usual[115].

Autoantibodies have been detected in non-autoimmune diseases such as asthma[117], chronic rhinosinusitis[118], idiopathic pulmonary fibrosis[119] and COPD[120]. IgE antibodies targeting self-antigens (auto allergy) are found in many autoimmune/inflammatory diseases[121], including systemic lupus erythematosus (SLE), Graves' disease, multiple sclerosis and rheumatoid arthritis. According to the PHM hypothesis, auto allergy could be the result of cross-reactions between colonizing PHMs and self-tissue.

The respiratory tract has been found to be involved in a number of autoimmune diseases, including rheumatoid arthritis, SLE and systemic sclerosis[122]. Epidemiological research shows that inflammatory bowel disease (IBD) is often preceded by airway diseases[123]. These findings are consistent with a connection between inhaled microbes and non-respiratory diseases.

Evidence linking stress to autoimmune diseases $[8,9,124]$ and allergic diseases $[38,125]$ has been accumulating. Elevated resting heart rate and low heart rate variability occur with increased stress[126,127] and have been associated with all-cause mortality[128-132]. Sleep disturbances, which may be related to stress, may predispose to the development of autoimmune disease[86]. 
Other components of the PHM hypothesis are also found commonly in CIDs. Specifically, opportunistic pathogens $[5,24,133,134]$ and/or dysbiosis[24,134,135] have been documented in many CIDs. Dietary alterations that would tend to reduce PHM exposure are showing benefit, as will be discussed in more detail in a later section.

An example of a CID that potentially fits the PHM hypothesis is sarcoidosis, a systemic disease marked by chronic granulomatous lung inflammation. It has been linked to mold exposure in damp buildings, and these damp buildings likely would have elevated PHM levels. A study[136] found evidence for increased sensitivity to fungal and bacterial antigens in sarcoidosis patients. There has also been research suggesting a causal role for bacterial infection[137,138]. Antifungal[139] and antibacterial[140,141] approaches in sarcoidosis have shown promise. Their limited success might result at least partly from some PHMs being less susceptible to most antimicrobials. This could be due to the potentially polyextremotolerant nature of PHMs, polymicrobial infections (e.g., requiring multiple antimicrobials), PHM-induced immune dysregulation and possible chronic PHM exposure. Although non-PHMs might also be involved, the PHM hypothesis predicts that the initiators of the disease process would be PHMs. Secondary opportunistic infections also occur[142].

Many IBD findings also appear to be consistent with the PHM hypothesis. IBD patients tend to have increased oxygen in their intestinal tract, resulting from inflammatory processes[143]. This leads to a greater abundance of oxygen-tolerant Proteobacteria and lower levels of microbial diversity[143,144]. The family Enterobacteriaceae, within the Proteobacteria, includes many pathogenic bacteria[144]. A reduction of species associated with anti-inflammatory effects is also observed[145]. An immune reaction to commensal microbes can occur as well, which might be due to the intestinal permeability and immune activation that develops[146]. Immunosuppressive drugs, an elemental diet and fecal microbiota transplants are approaches that shown some benefit in treating IBD[145].

It is not yet known what initiates the inflammatory processes and the other features of IBD. In one of the IBDs, Crohn's disease, an antibiotic combination targeting Mycobacterium avian subspecies paratuberculosis (MAP) infection has been reported to lead to long-term disease remission[147-151]. Agrawal et al[149] discuss recent promising data and addresses several common objections regarding MAP's role, making a compelling case for the involvement of MAP or similar species. It has also been suggested that other CIDs might be caused by MAP[152].

How MAP is acquired is still uncertain[153]. If its acquisition is related to a westernized diet or lifestyle it might itself be considered to be a PHM.

There has also been increasing evidence for the cold chain hypothesis for Crohn's disease, which postulates an inflammation-provoking role for Yersinia spp ingested from refrigerated food[41]. Substantiation of the MAP and cold chain hypotheses is hampered by the difficulty of detecting the implicated microbes and their relatively low pathogenicity.

Diverse IBD hypotheses could be seen as unified and explained by the PHM hypothesis. Both MAP and Yersinia spp could be viewed as opportunistic pathogens that take advantage of PHM-induced immune system dysregulation. Other microbes could contribute to disease as well (e.g., fungi[154]), and the particular species/strains involved could vary among individuals.

The anti-mycobacterial antibiotic approach targeting MAP shows signs of working best early in disease[151]. Perhaps this is because fewer PHMs and opportunistic infections that dysregulate/suppress the immune system have colonized and increased.

PHM-induced immune dysregulation or suppression postulated by the PHM hypothesis might be thought of as analogous to HIV weakening the immune system and leading to secondary infections. But in this case, the PHMs' effects on the immune system are proposed to be typically more subtle and the opportunistic infections may be harder to detect.

The PHM hypothesis can also explain the connection of IBD with a westernized diet[11], food reactions[155,156], allergic diseases[109,157-159] stress[160,161] and microbe-rich environment associated lung 
diseases[123,162]. The periodic exacerbations in IBD may often be due to variations in exposure to inhaled/ingested PHMs and/or stress from PHM reactions, sometimes combined with psychological stress[2]. Seasonal variation in IBD disease activity that appears to be linked to inhalant allergies has been found[158]. The implicated foods and inhalants may be associated with PHMs or might cross-react with PHMs. The PHM hypothesis can also potentially explain the reported effectiveness of varied dietary interventions in IBD (see diet section below).

Thus, looking at diverse types of observations, it appears that many CIDs are compatible with the PHM hypothesis. The evidence supporting the PHM hypothesis for a number of other CIDs is discussed in more detail elsewhere[2].

\section{Microbial allergy/hypersensitivity}

Fungal allergens have long been known. However, in recent years, non-fungal microbial allergens are increasingly being found[163,164]. A common bacterial plant pathogen, Pantoea agglomerans causes human respiratory diseases such as asthma and HP[165]. Farm environments have Archaea[166] that are capable of causing immune reactions[167]. IgE-mediated responses to viruses (i.e., HIV[94], varicella zoster[168,169], influenza virus[170] and parvovirus[171]) are also being found.

In Bachert et al's[172] review of chronic rhinosinusitis (CRS), the concept of bacterial allergy and colonization was one component of their proposed immune barrier hypothesis. Calenoff et al[173] found an elevated level of bacterial allergy in CRS.

Microbial allergies are potentially increased by exposure to damp environments due to increased fungi and bacteria. Damp environments have been associated with the development or exacerbation of a range of respiratory diseases, such as asthma, hypersensitivity pneumonitis, allergic rhinitis and chronic rhinosinusitis[174].

Although dampness has been associated with increased disease rates, Mendell et al[174] found no clear relationships between disease features and measured microbial exposures. The PHM hypothesis suggests that low abundance PHMs would increase in damp environments and might be an important missing factor.

Researchers have noted inadequate research on bacteria in damp buildings[175,176]. Mycobacteria can cause greater immune responses and be just as serious a threat as molds[176]. A study of showerhead microbial biofilms found high levels of non tuberculous mycobacteria and other potential pathogens[177].

\section{Focal infection theory and bacterial allergy}

As mentioned previously, the PHM hypothesis has some similarity to the early version of the focal infection theory, which also included the concept of bacterial allergy[2]. Desensitization to bacterial allergens was tested in several clinical trials and appeared to be successful in treating several CIDs, including chronic colitis[178], allergic rhinitis[179] and asthma[180,181]. Research found that autologous bacteria induced chemotaxis of peripheral blood mononuclear cells in non-atopic asthmatics but not controls[182], suggesting a role for hypersensitivity to colonizing bacteria. A review[181] concluded that bacterial vaccines (immunotherapy) were useful in at least a proportion of asthma cases.

However, a later review concluded that the evidence did not sufficiently support immunotherapy for bacterial allergens in asthma[183]. The discrepancy might be explained by an increasing effect of diverse, low abundance microbes, leading to decreasing effectiveness of approaches that focus on only a few bacterial species.

The PHM hypothesis suggests that earlier researchers using bacterial vaccines may have been increasing the ability of the immune system to reduce bacterial colonization, thus reducing symptoms. Similarly, one might speculate that some forms of current allergen-specific immunotherapy may be stimulating the immune system to eliminate at least some PHMs that cross-react with the known inhalant or food allergens. The 
elimination of the colonizing microbes by the immune system might be what leads to desensitization and reduction or elimination of symptoms in a proportion of patients.

The variation in severity of allergic reactions might reflect the levels of colonizing PHMs. Asymptomatic sensitization to allergens might be due to PHM colonization levels that are below the threshold needed for a detectable reaction.

\section{Immunosuppressive therapies and disease persistence}

Immunosuppression is a frequently effective method for controlling symptoms in many CIDs. It might be argued that if microbial colonization is the underlying cause, as proposed by the PHM hypothesis, then immunosuppressive therapies should be harmful. However, if the PHMs are relatively low virulence microbes and/or the immune responses against the PHMs are minimally effective or counterproductive, immunosuppression may have more benefit than harm.

According to the PHM hypothesis, the ineffectiveness of the immune response against the PHMs in CIDs is supported by the usual persistence of CIDs. This ineffectiveness could be due to varied factors, including microbial toxins, the microbes' antigenic changes and the effects of heterologous immunity as discussed previously. Chronic PHM exposure or repeated reinfection could also play a role. The IgE and other immune responses may be generally protective but perhaps not effective in the context of colonization by multiple novel PHMs in a westernized environment.

\section{Occupational/built environment and xenobiotic exposures}

The role of the occupational environment seems to be important in many CIDs[184,185]. For example, farmworkers and those who have close contact with birds are more susceptible to hypersensitivity pneumonitis (HP)[186]. Occupational asthma and HP may be related to exposures to diverse substances, including chemicals, animal dander, plastic residue and fungi[187].

The PHM hypothesis proposes that occupational and xenobiotic related CIDs could at least sometimes be due to low level, often undetected PHM colonization. In some cases, microbial antigens and PHM colonization might be involved, in addition to the potentially synergistic effects of non-microbial antigens and xenobiotics.

New research is revealing high levels of unknown microbes in built environments[2,188,189]. A study using wearable sampling devices found over 2500 species, and nearly half of the DNA information could not be classified[190]. Gilbert et al[189] discussed how new materials and diverse chemicals used in buildings could provide unique selective pressures, potentially shaping microbial evolution. The new species/strains that could result would fit the category of novel PHMs and might be polyextremotolerant and more able to colonize humans.

Regarding experiments that evaluate the effect of xenobiotic exposures, it is worth considering microbes and/or their antigens that are probably present in the tested xenobiotics. So, it would be desirable for toxicological studies to take this into account.

This need to address microbial contamination has become apparent in an analogous situation in which microbial DNA is found in test kits used for microbiological assays[191]. Research using the test kits use controls and other methods so that reagent microbes do not bias the study results.

Thus, xenobiotic's effects could potentially result from a combination of the xenobiotic itself and xenobioticassociated microbes. Autoimmune diseases may develop years after xenobiotic exposure[4]. This could be partly explained, according to the PHM hypothesis, by the length of time needed for colonizing xenobioticassociated microbes to increase. Also, with long-term colonization, microbial mutations could occur that might aid microbial adaptation to the human tissue environment and pathogenicity. 


\section{Diet, the Intestinal Microbiota and the PHM Hypothesis}

There is an increasing appreciation of the role of diet in shaping the gut microbiota. Many dietary factors have been implicated in inflammation-related diseases[3]. However, it is proposed here that PHMs could be an important factor contributing to the effects of different diets. PHMs in food/beverages might explain the benefits achieved from apparently contradictory dietary approaches (e.g., low fat vs low carbohydrate approaches), as will be discussed below.

Evidence supporting the connection between the adoption of a more westernized diet and CIDs have come from studies in developing countries[10,192-195]. The asthma rate in a study in India, for example, was associated with greater consumption of sodas and sweets[196].

In inflammatory bowel disease research, some promising interventions involve avoidance of many components of a typical westernized diet. A recent review found that most environmental factors were only associated with IBD in certain ethnic groups or countries; however, a westernized diet was found to be the most ubiquitous environmental factor associated with IBD incidence[11]. The same group proposed a plant-based diet approach [197], finding patients that used this approach had a much lower rate of recurrence after remission.

A Crohn's disease exclusion diet has been developed that essentially eliminates gluten, dairy, soy, animal fats, processed meats, emulsifiers, canned and packaged products, coffee, chocolate and alcohol[198]. A recent randomized controlled trial[199] found that this diet combined with partial enteral nutrition was significantly more effective than exclusive enteral nutrition in Crohn's disease.

The PHM hypothesis predicts that foods that are consumed a long time after harvest, food additives, animal products, ultra-processed foods and fatty foods contain more PHMs. The fermentation of foods and beverages like alcohol, chocolate, coffee and tea, would give more opportunity for at least some PHMs to increase, which could be a problem for some individuals. Food additives and ultra-processed foods provide conditions for microbes during their processing that are different from less processed foods. The resulting differences in selective pressures could lead to increases in PHMs.

Animal agriculture could promote PHM colonization of animals in a manner analogous to how humans are proposed to be colonized. And since animals provide an environment similar to human tissue, animals potentially could contain more PHMs that could colonize humans. Conventionally-raised farm animals, living an animal version of a westernized lifestyle, would potentially be even more colonized with polyextremotolerant PHMs that could affect humans. This has been studied most extensively in the case of antibiotic resistant microbes that humans acquire from animal products due to the use of antibiotics in agriculture[200]. This research supports the idea that modern agricultural practices are shaping animal microbiotas in a way that impacts human health.

Vegan or vegetarian diets have been observed to be beneficial in asthma[201] and rheumatic disease[202,203]. Reduced levels of animal products are found in the Mediterranean diet, which appears to have beneficial effects in many diseases[204]. A healthy and long life span in particular societies consuming low levels of animal products has also been described[205].

Another food component that might contain more PHMs is fat from animals and plants. Fats might provide a particularly favorable environment for microbes adapted to petroleum products. The utilization of hydrocarbons associated with fossil fuels has been suggested to be linked to lipophilic and neurotropic tendencies in some polyextremotolerant black yeast[206]. Bacteria have recently been found in human adipose tissue, with bacterial abundance associated with inflammatory parameters[207-209]. It would be interesting to determine if some of these bacteria are associated with petroleum products or ingested sources of fats.

There is evidence that a low fat diet is beneficial in heart disease[210,211] and possibly multiple sclerosis[212,213]. It is possible that ingested fat and especially animal fat, could contain PHMs that contribute to disease in humans. 
Benefits from avoiding gluten, as recommended by diets like the above-mentioned diet for Crohn's disease, could be related to hypersensitivity to gluten. However, gluten has the potential to increase intestinal permeability, even in those without celiac disease[214,215], and may be a problem for that reason as well. This, and other factors that increase intestinal permeability[215,216], could facilitate PHM colonization.

Obesity has been linked to a westernized diet[217]. Obesity is also associated with inflammation and CIDs, such as asthma[218], allergic rhinitis[219], chronic rhinosinusitis[220] and several autoimmune diseases[221,222].

Low-fat diets and low-carbohydrate diets have demonstrated essentially equal success in reversing obesity[223]. A randomized controlled study comparing low-fat to low-carbohydrate diets found each diet was successful in a subset of study participants[224]. Analysis of genetic markers and baseline insulin secretion levels revealed no predictive relationships. The PHM hypothesis suggests that success in weight loss on a particular diet might stem from individual differences in colonizing PHMs.

Individuality was also evident in a study using continuous blood sugar monitoring since participants differed in the foods that caused the highest blood sugar increases [225]. The differences in blood sugar responses appeared to be at least partly related to features of the intestinal microbiota. According to the PHM hypothesis, the observed microbiota patterns could be related, directly or indirectly, to PHM colonization related effects.

Stress is known to increase blood sugar[226]. Thus, a blood sugar increase in response to a food might result from a stress response to PHM-related allergens in the food. It should also be noted that air pollution has also been linked to blood sugar elevation[227] and type 2 diabetes mellitus incidence[228,229]. According to the PHM hypothesis, air pollution likely contains PHM.

A recent study by Hall et al[230] showed that inpatient adults given a diet of ultra-processed food gained more weight than those given relatively unprocessed food with the same levels of fiber and macronutrients. The PHM hypothesis proposes that this might be at least partly due to a higher level of PHMs present in ultra-processed food.

Food cravings can be an important issue in weight loss. It has been speculated that some intestinal microbes might have an evolutionary advantage if they cause a craving for foods they use for fuel[231]. The PHM hypothesis suggests that this phenomenon might include a craving for foods that contain the microbes. In addition, for some people, a mild stress effect might occur in response to consuming food containing higher levels of PHMs. This could cause a temporary lift in mood that could contribute to food craving and overconsumption. Interestingly, consumption of ultra-processed foods has been linked to food addiction[232].

Diets that have garnered recent interest include so-called Paleolithic diets. These diets typically eliminate dairy, grains and legumes and encourage consumption of fruits, vegetables, nuts, meat and fish[233].

The autoimmune Paleolithic diet also involves avoidance of certain proposed inflammatory foods. The foods avoided include gluten, dairy, legumes, refined sugar, industrial seed oils and nightshade vegetables. An observational study found an improvement in endoscopic inflammation and symptoms in patients with IBD who were on this diet[233]. An approach that included a Paleolithic diet also led to improved health-related quality-of-life and symptom scores in Hashimoto's thyroiditis[234]. A modified Paleolithic diet was associated with significant improvements in a randomized controlled trial in relapsing remitting multiple sclerosis[235].

From the PHM hypothesis perspective, the various Paleolithic diet approaches' apparent success in these small initial studies might be due to reduction of PHMs partly via avoidance of ultra-processed foods. Encouragement of consumption of fresh fruits and vegetables is also common in these diets. Presumably, the sooner the food is consumed after harvesting, the less opportunity for PHMs to increase.

Plant-based or vegan versions of a Paleolithic diet have been proposed[236]. The previously mentioned findings supporting vegan, vegetarian, low fat and lower animal product diets would suggest that these alternative versions of a Paleolithic diet are worth studying. 
The role of past PHM colonization should also be considered. If the PHM hypothesis is correct, the foods/beverages consumed during the majority of the time prior to illness might contain PHMs that contribute to the disease. Thus, a diet that differs significantly from the patient's previous diet might be most helpful.

\section{Food Allergies and Hypersensitivities}

Traditional food allergy tests have revealed connections between food allergies and some CIDs. For instance, a study showed that multiple sclerosis patients with food allergy had greater disease severity than those without food allergy[237], however, conflicting results indicate the need for more research[238]. In a subset of rheumatoid arthritis patients, a study using skin prick testing for food allergy detection [239] found a number of foods that affected symptoms and inflammatory markers.

Some studies have shown CID benefits from the IgE-blocking drug, omalizumab[240-242]. And some authors have suggested that elimination diets may be an important approach in at least some CIDs[243,244]. A recent review of several types of diets used in inflammatory arthritis research suggested significant benefit from dietary approaches, but noted that more research is needed[245].

In 14 rheumatoid arthritis patients, intestinal fluid samples contained significantly increased food specific antibody levels (IgM, IgG, IgA)[244]. The immune system attack on joints was suggested to be driven by multiple modest food hypersensitivity reactions. Immune complex formation and cross-reactivity with selfantigen were proposed to result from the reactions. The authors noted that these modest reactions would have been missed by studies using brief tests of small amounts of foods. The PHM hypothesis suggests that colonizing PHMs that cross-react with the food antigens initiate the disease process.

Other variations on allergy testing methods have been evaluated. Examples include the basophil activation test[246] and local allergic reaction assessment based on measurements of local IgE levels[247]. Nasal allergen challenge tests reveal local IgE increases and may clarify mechanisms in some cases regarded as non-allergic rhinitis[247].

Another condition that has been studied in the context of diverse types of food reactions is irritable bowel syndrome (IBS) [248]. Although not traditionally considered to be an inflammatory disease, IBS has now been shown to be associated with CIDs[249-251]. A recent study showed functional gastrointestinal disorders, which include IBS, are associated with a pro-inflammatory state in the central nervous system, possibly mediated by the gut microbiota[252]. Mast cells have been found to be increased in the intestinal tract in IBS[253]. Food allergy and non-celiac gluten hypersensitivity have been found in subsets of IBS patients[254].

In IBS, an intervention based on the antigen leukocyte cellular activation test (ALCAT) test led to significant benefit in a double-blind randomized controlled trial[255]. A reduction in neutrophil elastase concentration was associated with symptom reduction in the intervention group. Eosinophil DNA release associated with protein kinase C signaling pathways was implicated in the reactions[256]. An ALCAT-based dietary intervention resulted in beneficial effects on body mass index, serum amyloid A and medical symptom questionnaire scores in a 4-week double-blind randomized controlled trial[257].

IBS research using confocal laser endoscopy found that reactions to foods involved eosinophil degranulation rather than the typical mast cell-mediated reactions[258]. After 6 months on an elimination diet based on the results, $68 \%$ of the patients showed at least $80 \%$ improvement.

It is interesting that current IBS dietary recommendations[248] include avoiding or limiting carbonated beverages, alcohol, tea and coffee as well as fatty and spicy foods. These are all items that would be expected to be higher in PHMs, as discussed above.

A controversial type of approach for determining foods that cause inflammation uses serum IgG4 levels. Elevated IgG4 antibodies specific for foods have been observed in some CIDs[259-261]. And dietary interventions based on these IgG4 levels have shown promise[156,260]. Thus, it appears possible that IgG4 specific 
to particular foods indicates chronic antigen-driven inflammation associated with those foods in some cases.

However, the dominant view is that IgG4 serves as an anti-inflammatory blocking antibody and may be a marker of tolerance. This view arises partly from the finding that IgG4 specific antibodies increase during allergen immunotherapy for IgE-mediated allergies[262]. The PHM hypothesis combined with recent research may help shed light on these apparently contradictory views.

Chronically elevated IgG4 is thought to be a sign of chronic antigenic stimulation[263]. Selective IgG4 deficiency is associated with frequent respiratory infections [264,265], which might suggest IgG4's importance in protection against infections.

When IgG4 is high in the serum, it can also be associated with repeated infections[266]. From the perspective of the PHM hypothesis, when the IgG4 is high, it could be reflecting the presence of chronic colonization with PHMs. This might dysregulate the immune system and lead to increased infections.

If a PHM is colonizing human tissues, there might be an elevation in IgG4 against the PHM's antigens. IgG4 specific food antigens or self-antigens might be detected, but they might be cross-reacting with the unrecognized PHMs, which could be the true causal factor, according to the PHM hypothesis.

Total serum IgG4 has been found to be elevated in a number of chronic inflammatory conditions (e.g., pemphigous vulgaris, myasthenia gravis, rheumatoid arthritis)[267]. The traditional view is that IgG4 is anti-inflammatory and not able to activate complement. However, recent research indicates that IgG4 can be proinflammatory and even bind complement under certain circumstances[268,269]. It may be generally relatively anti-inflammatory when compared to IgE, IgG1 or IgG3; however, in certain situations, IgG4 could still cause inflammation.

A study found that total serum IgE and IgG4 levels were correlated in atopic patients[270]. This finding is compatible with the PHM hypothesis perspective that both isotypes are part of the response to PHMs.

In IgG4-related disease, a recently recognized group of CIDs, the role of IgG4 is not yet clear[268]. A polyclonal IgG4 response to multiple environmental antigens, including food antigens, has been found[271]. The authors note that this is consistent with a lack of immune regulation, but does not exclude it being antigen-driven.

IgG4-related disease has been associated with occupations with higher exposures to xenobiotics, such as solvents and metal dusts[272]. According to the PHM hypothesis, xenobiotic-associated, low abundance colonizing PHMs could be a causal factor. Disease often develops late in life, possibly due to colonizing PHMs increasing over time and potentially mutating to become more pathogenic.

Thus, the research discussed above suggests that the significance of IgG4 elevation resulting from chronic antigenic stimulation depends on the circumstances, and may or may not lead to detectable symptoms. It would appear that food specific IgG4 tests need to be evaluated separately for each disease in well-controlled trials to adequately assess their utility.

Whether or not IgG4 elevation leads to symptoms in the short-term, they potentially could lead to long-term negative consequences due to immune suppression[263] in some cases, or inflammation[268] in others. The PHM hypothesis suggests that the long-term outcome would depend on the pathogenicity of the PHMs that the IgG4 are produced in response to, combined with host factors.

Overall, the PHM hypothesis proposes that apparent immune dysregulation in various CIDs often begins with the inadequate attempts of the neuroimmune system to induce avoidance or elimination of PHMs. And food hypersensitivity reactions are proposed to arise from food cross-reactions with PHMs that have colonized human tissues. 


\section{Acute infections and post-infectious syndromes}

As has been mentioned previously, according to the PHM hypothesis, PHM colonization and associated hypersensitivity and stress often lead to immune dysregulation and/or suppression. This could increase susceptibility to infections.

Cardiovascular disease, diabetes and chronic lung diseases have been associated with greater mortality from COVID-19[273]. These comorbid diseases have all been associated with low grade inflammation, air pollution, a westernized diet and increased levels of pathogenic or dysbiotic microbes[133,274-276]. It is interesting to consider whether the severe inflammatory component of COVID-19 could be related to an intensified immune reaction to some of these colonizing microbes. These microbes might be PHMs or opportunistic pathogens acquired secondary to PHM colonization.

The PHM hypothesis proposes that before the viral infection, the immune system was reacting to these colonizing/infecting microbes with low-grade inflammation. Changes in the cytokine milieu occurring due to severe acute respiratory syndrome coronavirus 2 (SARS-CoV-2) infection might result in the low-grade inflammatory response to the PHMs being transformed into a more intense inflammatory response (e.g., via isotype switching). This could potentially contribute to or cause the excessive inflammation in severe COVID-19. Elevated autoantibodies have recently been found in a proportion of severe COVID-19[277]. This might reflect increased reactions to PHMs that cross-react with self-tissue

Mast cells, traditionally known for their role in allergies, have been proposed to be a potential target in COVID-19 to address excessive immune reactions[278,279]. In fact, some early trials that targeted the mast-cell product histamine generated positive results[280-282]. These findings require validation in large, randomized controlled trials.

Mast cells are being implicated in chronic inflammatory conditions as well[283-285]. Beyond their role in allergy, mast cells have been recognized as having a protective role against a broad range of infectious agents[285]. The same may be true of IgE-mediated responses, which are also being implicated in protection against infections, as discussed above.

It may be relevant to consider the linkages that have been found between COPD and asthma and/or allergic conditions[286-289]. A study showed that $37 \%$ of adults between 65 and 86 years of age who had asthma or COPD had asthma-COPD overlap syndrome[290], which was associated with worse outcomes. The progression of asthma to asthma-COPD overlap syndrome increased with higher exposure to fine particulate matter[288] and workplace mold odor[291]. This is consistent with the PHM hypothesis in that these environments likely contain elevated PHM levels that could contribute to disease progression.

COPD's underdiagnosis[292] and frequent connections with allergy and/or asthma might be reason to investigate IgE levels in COVID-19. The potential for local IgE elevations without elevated IgE levels in the blood should also be considered[293].

Although patterns may differ with different viruses, IgE levels were found to be higher at the beginning of a viral respiratory infection, declining over the following 3 months[294]. However, perhaps the IgE levels would stay high or be even more elevated in at least some of the more severely ill COVID-19 patients and might contribute to the severity of the inflammation. IgE elevation was observed to persist longer after a viral infection if the patient was atopic[294]. Interestingly, there is some evidence that IgE-targeting omalizumab is protective in viral infections[295,296]. A patient with asthma who was taking omalizumab was reported to recover from COVID-19 without undergoing any severe effects[295]. This topic requires further investigation.

Liu et al[133] found that disease occurrence, exacerbation frequency and inflammatory markers, such as IL-6 and IL-8, were associated with an increase in pathogenic fungi in COPD patients' lungs. The PHM hypothesis suggests that these pathogenic species could be PHMs or occur secondary to PHMs' effects and might contribute to the greater susceptibility of COPD patients to severe COVID-19.

It is still unclear how often bacterial and fungal co-infections are involved in COVID-19[297,298]. A study[299] 
showed that bacterial DNA and LPS in the plasma was significantly higher in patients with the most severe disease. Bacterial DNA or LPS were also significantly correlated with inflammatory mediators, such as IL-6[299]. It is possible that this might be related, in some cases, to PHMs in various tissues that might be influencing the course of the disease. Of course, these are only speculative ideas to stimulate research, and the latest recommendations are that antibiotics and antifungals should be used judiciously in COVID-19[300].

Another possibility involving a bacterial or fungal strain as a factor in excessive inflammation in COVID19 was suggested recently[274]. It might be that another microbe that cross-reacts with SARS-CoV-2 is present in the alveoli or other tissues in some individuals with severe disease (L. Carrasco, UAM, personal communication). This cross-reacting microbe could be a PHM and might exhibit antimicrobial resistance, making recovery more difficult.

Relevant to the previous discussion of IgG4, Chen et al[301] suggested that IgG4-RD patients may be more susceptible to severe COVID-19. Also, elevated IgG4 was found in the fibrotic tissue of a surgically resected tracheal ring in a patient with severe COVID-19[302]. It might be that elevated IgG4 is a sign of chronic antigenic stimulation by PHMs, as discussed above. Thus, these findings might be supportive of a role for PHMs in COVID-19 severity.

Excessive inflammation can occur in connection with other infections, such as influenza and sepsis[303]. Perhaps an intensified reaction to PHMs might also contribute to the excessive inflammation in conditions such as these.

PHMs might also be considered in post-infectious syndromes or other diseases linked to infections, like multisystem inflammatory syndrome in children and adolescents resulting from COVID-19 (MIS-C). Afrin et al[304] proposed that MIS-C might be a form of mast cell activation syndrome. Mast cell stabilization was proposed as a treatment to relieve prolonged symptoms following acute infection with SARS-CoV-2[305]. It seems plausible, based on the PHM hypothesis, that mast cell activation syndrome could be occurring as a response to antigens from PHM colonizers[2].

Prolonged symptoms, often involving fatigue, following COVID-19 have been compared to other postinfectious entities[306]. Myalgic encephalomyelitis/chronic fatigue syndrome (ME/CFS) has been reported to often begin following an infection, stressful event and/or toxin exposure[307]. A study of ME/CFS patients found elevated blood Proteobacteria was part of a composite score associated with symptom severity[308]. One might speculate that this reflects increased blood PHM levels, since the phylum Proteobacteria includes diverse environmental microbes. Some ME/CFS patients have reported that diet changes have been helpful in symptom reduction[309-311], and a trial of a diet and nutrient intervention led to patient improvements[312].

It also is worth considering the relevance of recent insights into Kawasaki disease (KD), a disease that closely resembles the multisystem inflammatory response syndrome in children and adolescents associated with SARS-CoV-2 infection. KD has been suggested to be linked to gut dysbiosis[44,313], a westernized lifestyle/hygiene[44,313], westernization-associated variants of normal flora[44], autoimmune disease[314] and allergic disorders[315,316]. Some recent KD research has implicated a microbe or its toxin transported by tropospheric air currents, along with a triggering infection in genetically susceptible individuals[317,318].

Increasing cedar pollen has been associated with increasing KD and other diseases in Japan[319]. The role of pollen-associated PHMs might be worth investigating. Pollen-associated microbial communities have been found to be affected by urbanization-related pollution[320]. The potential for detrimental effects from hypothesized pollen-associated PHMs warrants investigation, especially given a recent study that found an association between pollen levels and cancer incidence[321].

Thus, the possible involvement of westernization-associated gut microbes, environmental microbes/antigens and triggering infections suggest that the PHM hypothesis is potentially applicable to KD. And the evidence for the involvement of an airborne component in $\mathrm{KD}$ causation is reminiscent of the apparent association between severe COVID-19 and air pollution[322-324]. 
Taken together, these findings are consistent with the hypothesis that PHM colonization could be the underlying cause or a factor in susceptibility or severity of a number of acute infections and their sequelae.

\section{Testing the PHM Hypothesis}

Fully validating the PHM hypothesis may prove challenging initially, since some of the microbes may be very low in abundance. In-depth analyses of the microbiotas of man-made products, xenobiotics, air pollution and agricultural products is needed. A more thorough assessment of colonizing microbes is an important goal. This would allow validation of this hypothesis through determining the sources of colonizing microbes and their associations with symptoms and pathogenesis.

Regarding COVID-19, studying the virus-induced effects on immune reactions to the tissue microbiota would be of interest. The microbiotas and immune reactions of COVID-19 patients could be compared to healthy controls and patients with the comorbid conditions who do not have COVID-19. One might find that those who recovered from COVID-19 more easily had fewer potential PHMs and/or a lower or more transient immune reaction to them.

According to the PHM hypothesis, allergies are often due to PHM colonization. Thus, allergy-suppressing modes of treatment might be evaluated, as discussed above, to help control excessive inflammation in COVID19. Both PHMs and secondary opportunistic pathogens that might be contributing to the inflammation could be sought and potentially targeted by antimicrobials or other approaches designed to affect the microbiota balance. Immune modulation designed to reduce reactions to PHMs might be appropriate. These approaches also might be investigated in those who are symptomatic months after COVID-19.

Laboratory studies in animal models have utility in many contexts and could help evaluate the PHM hypothesis. Animals used in studies that model diseases would also be affected by PHMs. It would be impossible to give them the same environmental conditions that they evolved to tolerate. However, one could vary the degree of exposure to PHMs using different types of food, water, soil and other exposures.

The effects of dietary interventions on health outcomes in CIDs could be assessed. The effects of length of time since harvest and other factors potentially affecting PHMs' abundances could be analyzed. Ideally, high resolution assessments of the food and human microbiomes would be included. Antimicrobial, immune modulatory and microbiota modulatory approaches could be assessed, alone or in combination with dietary approaches.

It would be useful to determine if plant microbial antigens cross-react with plant antigens to the same extent that human-associated microbes cross-react with human tissue antigens[100]. If they do, it would lend support to the PHM hypothesis proposal that microbes in food are involved in allergic diseases and other CIDs. Microbes that cross-react with particular allergens could then be sought and their relevance in disease processes investigated.

Many other types of studies could be done to evaluate various aspects of the PHM hypothesis[2]. For instance, epidemiological studies could look for associations of disease with PHMs. Experiments could investigate stress effects of PHM allergen exposure in humans or assess effects of microbes present in xenobiotics.

With regard to stress, the ability of PHM exposure to affect the perception and physiological effects of stress could be studied. Research has shown that food allergic individuals have greater histamine and tryptase release under cold pain stress[325] and this research could be expanded to look specifically at PHM colonization effects.

If the PHM hypothesis is correct, then reducing or eliminating PHM colonization would likely allow toleration of previously reaction-provoking foods and environmental exposures. This could be tested if antimicrobials, immunotherapy, probiotics, medications, diet change or other approaches could be shown to eliminate or reduce symptoms and the relevant PHMs. However, to be most useful, all relevant PHMs and opportunistic 
infections would need to be considered. This perspective is in accord with the increasing recognition of the importance of polymicrobial infections[24,54,326,327].

\section{Discussion}

To briefly summarize, the PHM hypothesis proposes that a subset of microbes that have increased in our environment due to a post-hunter-gatherer era lifestyle are able to colonize human tissues under certain circumstances. This could lead to immune reactions to the colonizing microbes inside the body and the crossreacting microbes and other antigens in the environment and food. PHMs' cross-reactions with self-tissue could lead to autoimmunity, especially in genetically predisposed individuals. Subsequent hypersensitivity reactions, stress responses and immune dysregulation could promote barrier breakdown and susceptibility to opportunistic pathogens, exacerbating inflammation further.

Although much of the research supporting this hypothesis could be explained by other hypotheses, this is not seen as a drawback. In fact, the diversity and complexity of the microbial and immune system interactions means that many other explanations and mechanisms are likely to be important. These other explanations may often be complementary to the PHM hypothesis. Many observed mechanistic explanations might be describing downstream or late-stage consequences of the effects of PHMs on aspects of microbial communities and human physiology.

The broad scope, unifying power and consistency with diverse observations makes this hypothesis worth consideration. This is especially important because, in many cases, lower abundance PHMs with patchy distributions will not be detected unless research uses methods that focus on improving resolution. Examples of attempts to improve resolution are the focused approach used to assess Yersinia spp abundance[41], culturomics approaches[25,328] and approaches arising from methodological advances[329-331].

It is interesting to reflect on mast cells, which are best known for two types of activities. The historically recognized role of mast cells is in hypersensitivity reactions. Their more recently understood role is their part in the defense against numerous pathogens, including bacteria[332]. IgE, basophils and eosinophils are also involved in allergy and increasingly being recognized for their roles in fighting infection by many pathogens, not just parasites[95,333-335]. The dual role of the other 3 traditionally recognized non-IgE types of immune hypersensitivity reactions is also known, as they all can be involved in infections and hypersensitivity[336].

The PHM hypothesis is consistent with the idea that in many cases, these two roles (anti-infection and hypersensitivity) are really the same. The main difference, according to the PHM hypothesis, is that in diseases attributed primarily to hypersensitivity reactions or chronic inflammation, the causal microbes have not yet been identified and/or recognized.

Low level colonization may have a disproportionately large effect via cross-reactions with self-tissue, environmental microbes/substances and food components. In addition, there may be many PHMs involved, with additive effects. These features, which could allow low abundance microbes to have substantial effects, are proposed to be a large part of the reason that the effects of PHMs have been previously underestimated.

In the case of autoimmune disease, the potential role for cross-reacting microbes has long been appreciated. This is mainly due to the well-known example of Streptococcus pyogenes cross-reacting with heart tissue, which has been associated with tissue destruction in rheumatic heart disease[35].

In the case of allergy, cross-reactions between inhalants and foods are widely recognized in the form of oral allergy syndromes[337]. And there has been a growing appreciation of microbial allergy, as discussed in previous sections.

The PHM hypothesis posits that many, or possibly most CIDs could stem from PHM colonization that develops and increases over the years. The frequency of cross-reactions and diversity of microbial species/strains 
suggests that there may be foods, inhalants, self-tissues, colonizing and environmental microbes involved in a single reaction in some cases.

Although there is much evidence that is consistent with the PHM hypothesis, there is not enough evidence to validate it. The point of this article is to bring awareness to the plausibility and explanatory potential of the PHM hypothesis so that it can be evaluated.

Diverse treatment approaches are worth examining in relation to the PHM hypothesis, including antimicrobials, immune modulating medications, allergen specific immunotherapy, probiotics, diet, lifestyle, stress reduction techniques and altering environmental exposures. Approaches that have several components might be the most broadly effective, like combining antimicrobial approaches with diet and lifestyle approaches. The best approach in each disease would probably vary.

It would be important to distinguish between approaches that eliminate PHM colonization and those that just reduce reactions to PHMs. If elimination of PHM colonization is not feasible, other approaches that mitigate damaging effects might be emphasized.

If the PHM hypothesis is validated, the challenges that would ensue might not be as difficult as they might seem initially. If the identities and characteristics of the important PHMs and the immune responses to them are better understood, then more effective treatment approaches can be crafted. If the health problems associated with westernization are microbial in origin, there is likely a wide array of approaches available due to the power of the immune system, microbiotas and the treatments that affect them.

In conclusion, the PHM hypothesis proposes that colonization by microbes associated with a post-huntergatherer lifestyle, and especially a westernized lifestyle, underlie many CIDs. Additionally, immune hypersensitivities, cross-reactions, stress effects and opportunistic infections would typically result from PHM colonization and exacerbate the disease processes.

The PHM hypothesis arguably accounts for more of the basic research and clinical trial results in varied chronic inflammatory diseases than any other hypothesis. Given the adaptability of microbes, the changes in microbial exposures, the selection pressures for more polyextremotolerant microbes, and the frequency of cross-reactions, it seems reasonable to test the PHM hypothesis. If validated, it could lead to reduced morbidity and mortality through treatment approaches that could also minimize the need for permanent diet/lifestyle changes.

\section{Funding}

This research had no external funding.

\section{Acknowledgements}

I thank Peter Kramer, M.D., and Ian Roberts-Thomson, M.D., for helpful comments on an earlier version of this article. I thank David Waterhouse, Ph.D., for editorial assistance.

\section{Competing interests}

JCW will be involved with a company that will conduct and/or promote research related to this hypothesis and may file for patents related to the concepts presented here.

\section{References}

[1] Rappaport SM. Genetic Factors Are Not the Major Causes of Chronic Diseases. PLoS One 2016;11:e0154387. doi:10.1371/journal.pone.0154387.

[2] Waterhouse J. Post-hunter-gatherer era microbes' role in allergic, autoimmune and chronic inflammatory diseases. Authorea Prepr 2020. doi:10.22541/au.159113798.83363067. 
[3] Rinninella E, Raoul P, Cintoni M, Franceschi F, Miggiano GAD, Gasbarrini A, et al. What is the Healthy Gut Microbiota Composition? A Changing Ecosystem across Age, Environment, Diet, and Diseases. Microorganisms 2019;7:14. doi:10.3390/microorganisms7010014.

[4] Pollard KM, Christy JM, Cauvi DM, Kono DH. Environmental Xenobiotic Exposure and Autoimmunity. Curr Opin Toxicol 2018;10:15-22. doi:10.1016/j.cotox.2017.11.009.

[5] Arleevskaya MI, Kravtsova OA, Lemerle J, Renaudineau Y, Tsibulkin AP. How Rheumatoid Arthritis Can Result from Provocation of the Immune System by Microorganisms and Viruses. Front Microbiol 2016;7:1296. doi:10.3389/fmicb.2016.01296.

[6] Hugot JP, Alberti C, Berrebi D, Bingen E, Cézard JP. Crohn's disease: the cold chain hypothesis. Lancet (London, England) 2003;362:2012-5. doi:10.1016/S0140-6736(03)15024-6.

[7] Benito-León J, Laurence M. The Role of Fungi in the Etiology of Multiple Sclerosis. Front Neurol 2017;8:535. doi:10.3389/fneur.2017.00535.

[8] Yamada Y, Tatsumi K, Yamaguchi T, Tanabe N, Takiguchi Y, Kuriyama T, et al. Influence of stressful life events on the onset of sarcoidosis. Respirology 2003;8:186-91. doi:10.1046/j.1440-1843.2003.00456.x.

[9] Song H, Fang F, Tomasson G, Arnberg FK, Mataix-Cols D, Cruz LF de la, et al. Association of Stress-Related Disorders With Subsequent Autoimmune Disease. JAMA 2018;319:2388-400. doi:10.1001/jama.2018.7028.

[10] Manzel A, Muller DN, Hafler DA, Erdman SE, Linker RA, Kleinewietfeld M. Role of "Western Diet" in Inflammatory Autoimmune Diseases. Curr Allergy Asthma Rep 2014;14:404. doi:10.1007/s11882-013-0404-6.

[11] Chiba M, Nakane K, Komatsu M. Westernized Diet is the Most Ubiquitous Environmental Factor in Inflammatory Bowel Disease. Perm J 2019;23:18-107. doi:10.7812/TPP/18-107.

[12] Strachan DP. Hay fever, hygiene, and household size. BMJ 1989;299:1259-60. doi:10.1136/bmj.299.6710.1259.

[13] Rook GAW. 99th Dahlem Conference on Infection, Inflammation and Chronic Inflammatory Disorders: Darwinian medicine and the 'hygiene' or 'old friends' hypothesis. Clin Exp Immunol 2010;160:70-9. doi:10.1111/j.1365-2249.2010.04133.x.

[14] Shreiner A, Huffnagle GB, Noverr MC. The "Microflora Hypothesis" of Allergic Disease. Adv Exp Med Biol 2008;635:113-34. doi:10.1007/978-0-387-09550-9_10.

[15] Blaser MJ. Missing microbes : how the overuse of antibiotics is fueling our modern plagues. 1st ed. NY, NY: Holt; 2015.

[16] Dani A. Colonization and infection. Cent Eur J Urol 2014;67:86-7. doi:10.5173/ceju.2014.01.art19.

[17] Profet M. The function of allergy: immunological defense against toxins. Q Rev Biol 1991;66:23-62. doi:10.1086/417049.

[18] Palm NW, Rosenstein RK, Medzhitov R. Allergic Host Defenses. Nature 2012;484:465-72. doi:10.1038/nature11047.

[19] Tsai M, Starkl P, Marichal T, Galli SJ. Testing the "toxin hypothesis of allergy": Mast cells, IgE, and innate and acquired immune responses to venoms. Curr Opin Immunol 2015;36:80-7. doi:10.1016/j.coi.2015.07.001.

[20] Daschner A, Gonzalez Fernandez J. Allergy in an Evolutionary Framework. J Mol Evol 2020;88:66-76. doi:10.1007/s00239-019-09895-3.

[21] Sherman PW, Holland E, Sherman JS. Allergies: their role in cancer prevention. Q Rev Biol 2008;83:33962. doi:10.1086/592850. 
[22] Daschner A. An Evolutionary-Based Framework for Analyzing Mold and Dampness-Associated Symptoms in DMHS. Front Immunol 2017;7:672. doi:10.3389/fimmu.2016.00672.

[23] Sharma S, Thomas PG. The two faces of heterologous immunity: protection or immunopathology. J Leukoc Biol 2014;95:405-16. doi:10.1189/jlb.0713386.

[24] Earl CS, An S, Ryan RP. The changing face of asthma and its relation with microbes. Trends Microbiol 2015;23:408-18. doi:10.1016/j.tim.2015.03.005.

[25] Lagier J-C, Armougom F, Million M, Hugon P, Pagnier I, Robert C, et al. Microbial culturomics: paradigm shift in the human gut microbiome study. Clin Microbiol Infect 2012;18:1185-93. doi:10.1111/14690691.12023.

[26] Sogin ML, Morrison HG, Huber JA, Welch DM, Huse SM, Neal PR, et al. Microbial diversity in the deep sea and the underexplored "rare biosphere." Proc Natl Acad Sci U S A 2006;103:12115-20. doi:10.1073/pnas.0605127103.

[27] Chao A, Hsieh TC, Chazdon RL, Colwell RK, Gotelli NJ. Unveiling the species-rank abundance distribution by generalizing the Good-Turing sample coverage theory. Ecology 2015;96:1189-201. doi:10.1890/140550.1 .

[28] Jousset A, Bienhold C, Chatzinotas A, Gallien L, Gobet A, Kurm V, et al. Where less may be more: how the rare biosphere pulls ecosystems strings. ISME J 2017;11:853-62. doi:10.1038/ismej.2016.174.

[29] Tett A, Pasolli E, Farina S, Truong DT, Asnicar F, Zolfo M, et al. Unexplored diversity and strainlevel structure of the skin microbiome associated with psoriasis. NPJ Biofilms Microbiomes 2017;3:14. doi:10.1038/s41522-017-0022-5.

[30] Fischer M, Strauch B, Renard BY. Abundance estimation and differential testing on strain level in metagenomics data. Bioinformatics, vol. 33, 2017, p. i124-32. doi:10.1093/bioinformatics/btx237.

[31] Bui FQ, Almeida-da-Silva CLC, Huynh B, Trinh A, Liu J, Woodward J, et al. Association between periodontal pathogens and systemic disease. Biomed J 2019;42:27-35. doi:10.1016/j.bj.2018.12.001.

[32] Dominy SS, Lynch C, Ermini F, Benedyk M, Marczyk A, Konradi A, et al. Porphyromonas gingivalis in Alzheimer's disease brains: Evidence for disease causation and treatment with small-molecule inhibitors. Sci Adv 2019;5:eaau3333. doi:10.1126/sciadv.aau3333.

[33] Casadevall A, Pirofski L. Accidental Virulence, Cryptic Pathogenesis, Martians, Lost Hosts, and the Pathogenicity of Environmental Microbes. Eukaryot Cell 2007;6:2169-74. doi:10.1128/EC.00308-07.

[34] Babič MN, Gostinčar C, Gunde-Cimerman N. Microorganisms populating the water-related indoor biome. Appl Microbiol Biotechnol 2020;104:6443-62. doi:10.1007/s00253-020-10719-4.

[35] Root-Bernstein R, Fairweather D. Unresolved issues in theories of autoimmune disease using myocarditis as a framework. J Theor Biol 2015;375:101-23. doi:10.1016/j.jtbi.2014.11.022.

[36] Pendala S, Walker JM, Holt PR. A High-Fat Diet Is Associated With Endotoxemia That Originates From the Gut. Gastroenterology 2012;142:1100-1101.e1. doi:10.1053/j.gastro.2012.01.034.

[37] Guo Y, Bian X, Liu J, Zhu M, Li L, Yao T, et al. Dietary Components, Microbial Metabolites and Human Health: Reading between the Lines. Foods 2020;9:1045. doi:10.3390/foods9081045.

[38] Dave ND, Xiang L, Rehm KE, Marshall GD, Jr. Stress and Allergic Diseases. Immunol Allergy Clin North Am 2011;31:55-68. doi:10.1016/j.iac.2010.09.009.

[39] Sherbet G. Bacterial Infections and the Pathogenesis of Autoimmune Conditions. Br J Med Pract $2009 ; 2: 6-13$.

[40] Mattman LH. Cell wall deficient forms : stealth pathogens. 3rd ed. Boca Raton, FL: CRC Press; 2001. 
[41] Hugot JP, Dumay A, Barreau F, Meinzer U. Crohn's disease: is the cold chain hypothesis still hot? J Crohn's Colitis 2020. doi:10.1093/ecco-jcc/jjaa192.

[42] Tenailleau QM, Lanier C, Gower-Rousseau C, Cuny D, Deram A, Occelli F. Crohn's disease and environmental contamination: Current challenges and perspectives in exposure evaluation 2020. doi:10.1016/j.envpol.2020.114599.

[43] Roberts-Thomson IC, Bryant R V, Costello SP. Uncovering the cause of ulcerative colitis. JGH Open 2019;3:274-6. doi:10.1002/jgh3.12216.

[44] Lee KY, Han JW, Lee JS. Kawasaki disease may be a hyperimmune reaction of genetically susceptible children to variants of normal environmental flora. Med Hypotheses 2007;69:642-51. doi:10.1016/j.mehy.2006.12.051.

[45] Bhattacharyya M, Ghosh T, Shankar S, Tomar N. The conserved phylogeny of blood microbiome. Mol Phylogenet Evol 2017;109:404-8. doi:10.1016/j.ympev.2017.02.001.

[46] Whittle E, Leonard MO, Harrison R, Gant TW, Tonge DP. Multi-Method Characterization of the Human Circulating Microbiome. Front Microbiol 2019;9:3266. doi:10.3389/fmicb.2018.03266.

[47] Castillo DJ, Rifkin RF, Cowan DA, Potgieter M. The Healthy Human Blood Microbiome: Fact or Fiction? Front Cell Infect Microbiol 2019;9:148. doi:10.3389/fcimb.2019.00148.

[48] Dickson RP, Martinez FJ, Huffnagle GB. The Role of the Microbiome in Exacerbations of Chronic Lung Diseases. Lancet 2014;384:691-702. doi:10.1016/s0140-6736(14)61136-3.

[49] Hammad DBM, Tonge DP. Molecular Characterisation of the Synovial Fluid Microbiome. PLoS One 2019;14:e0225110. doi:10.1371/journal.pone.0225110.

[50] Branton WG, Ellestad KK, Maingat F, Wheatley BM, Rud E, Warren RL, et al. Brain Microbial Populations in HIV/AIDS: $\alpha$-Proteobacteria Predominate Independent of Host Immune Status. PLoS One 2013;8:e54673. doi:10.1371/journal.pone.0054673.

[51] Branton WG, Lu JQ, Surette MG, Holt RA, Lind J, Laman JD, et al. Brain microbiota disruption within inflammatory demyelinating lesions in multiple sclerosis. Sci Rep 2016;6:37344. doi:10.1038/srep37344.

[52] Kriesel JD, Bhetariya P, Wang Z-M, Renner D, Palmer C, Fischer KF. Spectrum of Microbial Sequences and a Bacterial Cell Wall Antigen in Primary Demyelination Brain Specimens Obtained from Living Patients. Sci Rep 2019;9:1387. doi:10.1038/s41598-018-38198-8.

[53] Alonso R, Pisa D, Carrasco L. Searching for Bacteria in Neural Tissue From Amyotrophic Lateral Sclerosis. Front Neurosci 2019;13:171. doi:10.3389/fnins.2019.00171.

[54] Carrasco L, Pisa D, Alonso R. Polymicrobial Infections and Neurodegenerative Diseases. Curr Clin Microbiol Reports 2020;7:20-30. doi:10.1007/s40588-020-00139-3.

[55] Whittle E, Leonard MO, Harrison R, Gant TW, Tonge DP. Multi-Method Characterisation of the Human Circulating Microbiome. Front Microbiol 2019;17:3266. doi:10.1101/359760.

[56] Domagal-Goldman SD, Wright KE, Adamala K, Arina de la Rubia L, Bond J, Dartnell LR, et al. The Astrobiology Primer v2.0. Astrobiology 2016;16:561-653. doi:10.1089/ast.2015.1460.

[57] Vaishampayan P, Probst AJ, La Duc MT, Bargoma E, Benardini JN, Andersen GL, et al. New perspectives on viable microbial communities in low-biomass cleanroom environments. ISME J 2013;7:312-24. doi:10.1038/ismej.2012.114.

[58] Mogul R, Barding GA, Lalla S, Lee S, Madrid S, Baki R, et al. Metabolism and Biodegradation of Spacecraft Cleaning Reagents by Strains of Spacecraft-Associated Acinetobacter. Astrobiology 2018;18:151727. doi:10.1089/ast.2017.1814. 
[59] Casadevall A, Steenbergen JN, Nosanchuk JD. "Ready made" virulence and "dual use" virulence factors in pathogenic environmental fungi - the Cryptococcus neoformans paradigm. Curr Opin Microbiol 2003;6:332-7. doi:10.1016/S1369-5274(03)00082-1.

[60] Casadevall A, Pirofski L. Benefits and Costs of Animal Virulence for Microbes. MBio 2019;10:e00863-19. doi:10.1128/mBio.00863-19.

[61] Lee HS. Diversity of halophilic archaea in fermented foods and human intestines and their application. J Microbiol Biotechnol 2013;23:1645-53. doi:10.4014/jmb.1308.08015.

[62] Gibtan A, Park K, Woo M, Shin J-K, Lee DW, Sohn JH, et al. Diversity of Extremely Halophilic Archaeal and Bacterial Communities from Commercial Salts. Front Microbiol 2017;8:799. doi:10.3389/fmicb.2017.00799.

[63] Zajc J, Gunde-Cimerman N. The Genus Wallemia-From Contamination of Food to Health Threat. Microorganisms 2018;6:46. doi:10.3390/microorganisms6020046.

[64] Newman KL, Newman LS. Occupational Causes of Sarcoidosis. Curr Opin Allergy Clin Immunol 2012;12:145-50. doi:10.1097/ACI.0b013e3283515173.

[65] Pauly JL, Paszkiewicz G. Cigarette smoke, bacteria, mold, microbial toxins, and chronic lung inflammation. J Oncol 2011;2011:819129. doi:10.1155/2011/819129.

[66] Kobziar LN, Pingree MRA, Larson H, Dreaden TJ, Green S, Smith JA. Pyroaerobiology: the aerosolization and transport of viable microbial life by wildland fire. Ecosphere 2018;9:e02507. doi:10.1002/ecs2.2507.

[67] Moore RA, Bomar C, Kobziar LN, Christner BC. Wildland fire as an atmospheric source of viable microbial aerosols and biological ice nucleating particles. ISME J 2020:1-12. doi:10.1038/s41396-020-007888.

[68] Happo MR, Sippula O, Jalava PI, Rintala H, Leskinen A, Komppula M, et al. Role of microbial and chemical composition in toxicological properties of indoor and outdoor air particulate matter. Part Fibre Toxicol 2014;11:60. doi:10.1186/s12989-014-0060-6.

[69] Gutarowska B, Szulc J, Nowak A, Otlewska A, Okrasa M, Jachowicz A, et al. Dust at Various Workplaces-Microbiological and Toxicological Threats. Int J Environ Res Public Health 2018;15:877. doi:10.3390/ijerph15050877.

[70] Li H, Zhou XY, Yang XR, Zhu YG, Hong YW, Su JQ. Spatial and seasonal variation of the airborne microbiome in a rapidly developing city of China. Sci Total Environ 2019;665:61-8. doi:10.1016/j.scitotenv.2019.01.367.

[71] Qin T, Zhang F, Zhou H, Ren H, Du Y, Liang S, et al. High-Level PM2.5/PM10 Exposure Is Associated With Alterations in the Human Pharyngeal Microbiota Composition. Front Microbiol 2019;10:54. doi:10.3389/fmicb.2019.00054.

[72] Hesselmar B, Hicke-Roberts A, Wennergren G. Allergy in Children in Hand Versus Machine Dishwashing. Pediatrics 2015;135:e590-7.

[73] Cheng LE, Cabana MD. Dishing It Out to Allergies. Pediatrics 2015;135:e707-8.

[74] Beceiro A, Tomás M, Bou G. Antimicrobial Resistance and Virulence: a Successful or Deleterious Association in the Bacterial World? Clin Microbiol Rev 2013;26:185-230. doi:10.1128/CMR.00059-12.

[75] Mattman LH. Cell wall-deficient forms of mycobacteria. Ann N Y Acad Sci 1970;174:852-61. doi:10.1111/j.1749-6632.1970.tb45604.x.

[76] Potgieter M, Bester J, Kell DB, Pretorius E. The dormant blood microbiome in chronic, inflammatory diseases. FEMS Microbiol Rev 2015;39:567-91. doi:10.1093/femsre/fuv013. 
[77] Markova N. Dysbiotic microbiota in autistic children and their mothers: persistence of fungal and bacterial wall-deficient L-form variants in blood. Sci Rep 2019;9:13401. doi:10.1038/s41598-019-49768-9.

[78] Sampson HA. Food allergy: Past, present and future. Allergol Int 2016;65:363-9. doi:10.1016/j.alit.2016.08.006.

[79] Cserháti E. The history of bronchial asthma from the ancient times till the Middle Ages. Acta Physiol Hung 2004;91:243-61. doi:10.1556/APhysiol.91.2004.3-4.8.

[80] Entezami P, Fox DA, Clapham PJ, Chung KC. Historical Perspective on the Etiology of Rheumatoid Arthritis. Hand Clin 2011;27:1-10. doi:10.1016/j.hcl.2010.09.006.

[81] Costa-Pinto FA, Basso AS, Russo M. Role of mast cell degranulation in the neural correlates of the immediate allergic reaction in a murine model of asthma. Brain Behav Immun 2007;21:783-90. doi:10.1016/j.bbi.2007.01.002.

[82] Tonelli LH, Katz M, Kovacsics CE, Gould TD, Joppy B, Hoshino A, et al. Allergic rhinitis induces anxiety-like behavior and altered social interaction in rodents. Brain Behav Immun 2009;23:784-93. doi:10.1016/j.bbi.2009.02.017.

[83] Costa-Pinto FA, Basso AS, Britto LRG, Malucelli BE, Russo M. Avoidance behavior and neural correlates of allergen exposure in a murine model of asthma. Brain Behav Immun 2005;19:52-60. doi:10.1016/j.bbi.2004.02.005.

[84] Manalai P, Hamilton RG, Langenberg P, Kosisky SE, Lapidus M, Sleemi A, et al. Pollen-specific immunoglobulin $\mathrm{E}$ positivity is associated with worsening of depression scores in bipolar disorder patients during high pollen season. Bipolar Disord 2012;14:90-8. doi:10.1111/j.1399-5618.2012.00983.x.

[85] Kelly K, Ratliff S, Mezuk B. Allergies, asthma, and psychopathology in a nationally-representative US sample. J Affect Disord 2019;251:130-5. doi:10.1016/j.jad.2019.03.026.

[86] Hsiao YH, Chen YT, Tseng CM, Wu LA, Lin WC, Su VYF, et al. Sleep Disorders and Increased Risk of Autoimmune Diseases in Individuals without Sleep Apnea. Sleep 2015;38:581-6. doi:10.5665/sleep.4574.

[87] Zielinski MR, Systrom DM, Rose NR. Fatigue, sleep, and autoimmune and related disorders. Front Immunol 2019;10:1827. doi:10.3389/fimmu.2019.01827.

[88] Schneiderman N, Ironson G, Siegel SD. Stress and Health: Psychological, Behavioral, and Biological Determinants. Annu Rev Clin Psychol 2005;1:607-28. doi:10.1146/annurev.clinpsy.1.102803.144141.

[89] Dhabhar FS, Malarkey WB, Neri E, McEwen BS. Stress-induced redistribution of immune cells - from barracks to boulevards to battlefields: a tale of 3 hormones. Psychoneuroendocrinology 2012;37:1345-68. doi:10.1016/j.psyneuen.2012.05.008.

[90] Geng S, Yang L, Cheng F, Zhang Z, Li J, Liu W, et al. Gut Microbiota Are Associated With Psychological Stress-Induced Defections in Intestinal and Blood-Brain Barriers. Front Microbiol 2020;10:3067. doi:10.3389/fmicb.2019.03067.

[91] Tsujita S, Morimoto K. Secretory IgA in Saliva can be a Useful Stress Marker. Environ Health Prev Med 1999;4:1-8. doi:10.1007/BF02931243.

[92] Phillips AC, Carroll D, Evans P, Bosch JA, Clow A, Hucklebridge F, et al. Stressful life events are associated with low secretion rates of immunoglobulin $\mathrm{A}$ in saliva in the middle aged and elderly. Brain Behav Immun 2006;20:191-7. doi:10.1016/j.bbi.2005.06.006.

[93] Richmond BW, Brucker RM, Han W, Du RH, Zhang Y, Cheng DS, et al. Airway bacteria drive a progressive COPD-like phenotype in mice with polymeric immunoglobulin receptor deficiency. Nat Commun 2016;7:11240. doi:10.1038/ncomms11240. 
[94] Pellegrino MG, Bluth MH, Smith-Norowitz T, Fikrig S, Volsky DJ, Moallem H, et al. HIV type 1specific IgE in serum of long-term surviving children inhibits HIV type 1 production in vitro. AIDS Res Hum Retroviruses 2002;18:363-72. doi:10.1089/088922202753519142.

[95] Bluth MH, Robin J, Ruditsky M, Norowitz KB, Chice S, Pytlak E, et al. IgE Anti-Borrelia burgdorferi Components (p18, p31, p34, p41, p45, p60) and Increased Blood CD8 ${ }^{+}$CD60 ${ }^{+}$T Cells in Children with Lyme Disease. Scand J Immunol 2007;65:376-82. doi:10.1111/j.1365-3083.2007.01904.x.

[96] Magen E, Schlesinger M, David M, Ben-Zion I, Vardy D. Selective IgE deficiency, immune dysregulation, and autoimmunity. Allergy Asthma Proc 2014;35:e27-33. doi:10.2500/aap.2014.35.3734.

[97] Smith JK, Krishnaswamy GH, Dykes R, Reynolds S, Berk SL. Clinical Manifestations of IgE Hypogammaglobulinemia. Ann Allergy, Asthma Immunol 1997;78:313-8. doi:10.1016/S1081-1206(10)63188-2.

[98] Magen E, Mishal J, Vardy D. Selective IgE deficiency and cardiovascular diseases. Allergy Asthma Proc 2015;36:225-9. doi:10.2500/aap.2015.36.3825.

[99] Ferastraoaru D, Gross R, Rosenstreich D. Increased malignancy incidence in IgE deficient patients not due to concomitant Common Variable Immunodeficiency. Ann Allergy, Asthma Immunol 2017;119:267-73. doi:10.1016/j.anai.2017.07.006.

[100] Trost B, Lucchese G, Stufano A, Bickis M, Kusalik A, Kanduc D. No human protein is exempt from bacterial motifs, not even one. Self Nonself 2010;1:328-34. doi:10.4161/self.1.4.13315.

[101] Bacher P, Hohnstein T, Beerbaum E, Röcker M, Blango MG, Kaufmann S, et al. Human Anti-fungal Th17 Immunity and Pathology Rely on Cross-Reactivity against Candida albicans. Cell 2019;176:13401355.e15. doi:10.1016/j.cell.2019.01.041.

[102] Sabino R, Faísca VM, Carolino E, Veríssimo C, Viegas C. Occupational exposure to Aspergillus by swine and poultry farm workers in Portugal. J Toxicol Environ Health A 2012;75:1381-91. doi:10.1080/15287394.2012.721170.

[103] Mousavi B, Hedayati MT, Hedayati N, Ilkit M, Syedmousavi S. Aspergillus species in indoor environments and their possible occupational and public health hazards. Curr Med Mycol 2016;2:36-52. doi:10.18869/acadpub.cmm.2.1.36.

[104] Fairs A, Agbetile J, Bourne M, Hargadon B, Monteiro WR, Morley JP, et al. Isolation of Aspergillus fumigatus from sputum is associated with elevated airborne levels in homes of patients with asthma. Indoor Air 2013;23:275-84. doi:10.1111/ina.12020.

[105] Hills RD, Jr., Pontefract BA, Mishcon HR, Black CA, Sutton SC, et al. Gut Microbiome: Profound Implications for Diet and Disease. Nutrients 2019;11:1613. doi:10.3390/nu11071613.

[106] Neuman H, Forsythe P, Uzan A, Avni O, Koren O. Antibiotics in early life: dysbiosis and the damage done. FEMS Microbiol Rev 2018;42:489-99. doi:10.1093/femsre/fuy018.

[107] Petersen J, Ciacchi L, Tran MT, Loh KL, Kooy-Winkelaar Y, Croft NP, et al. T cell receptor crossreactivity between gliadin and bacterial peptides in celiac disease. Nat Struct Mol Biol 2020;27:49-61. doi:10.1038/s41594-019-0353-4.

[108] Scales BS, Dickson RP, LiPuma JJ, Huffnagle GB. Microbiology, Genomics, and Clinical Significance of the Pseudomonas fluorescens Species Complex, an Unappreciated Colonizer of Humans. Clin Microbiol Rev 2014;27:927-48. doi:10.1128/CMR.00044-14.

[109] Thirumala Krishna M, Subramanian A, Adderley NJ, Zemedikun DT, Gkoutos G V, Nirantharakumar $\mathrm{K}$. Allergic diseases and long-term risk of autoimmune disorders: longitudinal cohort study and cluster analysis. Eur Respir J 2019;54:1900476. doi:10.1183/13993003.00476-2019. 
[110] Klamt S, Vogel M, Kapellen TM, Hiemisch A, Prenzel F, Zachariae S, et al. Association between IgEmediated allergies and diabetes mellitus type 1 in children and adolescents. Pediatr Diabetes 2015;16:493-503. doi:10.1111/pedi.12298.

[111] Seiskari T, Viskari H, Kondrashova A, Haapala AM, Ilonen J, Knip M, et al. Co-occurrence of allergic sensitization and type 1 diabetes. Ann Med 2010;42:352-9. doi:10.3109/07853890.2010.481678.

[112] Chen YH, Lin CL, Bau DT, Hung YC. The risk of allergic conjunctivitis in patients with type 1 diabetes mellitus: a population-based retrospective cohort study. BMJ Open 2017;7:e015795. doi:10.1136/bmjopen2016-015795.

[113] Krischer JP, Cuthbertson D, Couluris M, Knip M, Virtanen SM. Association of diabetes-related autoantibodies with the incidence of asthma, eczema and allergic rhinitis in the TRIGR randomised clinical trial. Diabetologia 2020;63:1796-1807. doi:10.1007/s00125-020-05188-3.

[114] Mustonen N, Siljander H, Peet A, Tillmann V, Härkönen T, Niemelä O, et al. Coeliac disease and HLAconferred susceptibility to autoimmunity are associated with IgE sensitization in young children. Allergy 2020;75:692-4. doi:10.1111/all.14055.

[115] Avrameas S, Alexopoulos H, Moutsopoulos HM. Natural autoantibodies: An undersung hero of the immune system and autoimmune disorders-A point of view. Front Immunol 2018;9:1320. doi:10.3389/fimmu.2018.01320.

[116] Rivera-Correa J, Rodriguez A. Divergent Roles of Antiself Antibodies during Infection. Trends Immunol 2018;39:515-22. doi:10.1016/j.it.2018.04.003.

[117] Tedeschi A, Asero R. Asthma and autoimmunity: a complex but intriguing relation. Expert Rev Clin Immunol 2008;4:767-76. doi:10.1586/1744666X.4.6.767.

[118] Macri GF, Greco A, Marinelli C, Gallo A, Fusconi M, De Virgilio A, et al. Evidence and Role of Autoantibodies in Chronic Rhinosinusitis with Nasal Polyps. Int J Immunopathol Pharmacol 2014;27:15561. doi:10.1177/039463201402700202.

[119] Kamiya H, Panlaqui OM. Prognostic significance of autoantibodies for idiopathic pulmonary fibrosis: protocol for a systematic review. BMJ Open 2018;8:e020862. doi:10.1136/bmjopen-2017-020862.

[120] Wen L, Krauss-Etschmann S, Petersen F, Yu X. Autoantibodies in Chronic Obstructive Pulmonary Disease. Front Immunol 2018;9:66. doi:10.3389/fimmu.2018.00066.

[121] Maurer M, Altrichter S, Schmetzer O, Scheffel J, Church MK, Metz M. Immunoglobulin E-mediated autoimmunity. Front Immunol 2018;9:689. doi:10.3389/fimmu.2018.00689.

[122] Cojocaru M, Cojocaru IM, Silosi I, Vrabie CD. Pulmonary manifestations of systemic autoimmune diseases. Maedica (Buchar) 2011;6:224-9.

[123] Vutcovici M, Brassard P, Bitton A. Inflammatory bowel disease and airway diseases. World J Gastroenterol 2016;22:7735-41. doi:10.3748/wjg.v22.i34.7735.

[124] Abdul Rani R, Raja Ali RA, Lee YY. Irritable bowel syndrome and inflammatory bowel disease overlap syndrome: pieces of the puzzle are falling into place. Intest Res 2016;14:297-300. doi:10.5217/ir.2016.14.4.297.

[125] Lee M-R, Son B-S, Park Y-R, Kim H-M, Moon J-Y, Lee Y-J, et al. The Relationship Between Psychosocial Stress and Allergic Disease Among Children and Adolescents in Gwangyang Bay, Korea. J Prev Med Public Heal 2012;45:374-80. doi:10.3961/jpmph.2012.45.6.374.

[126] Lee JM, Kim HC, Kang JI, Suh I. Association between stressful life events and resting heart rate. BMC Psychol 2014;2:29. doi:10.1186/s40359-014-0029-0.

[127] Kim HG, Cheon EJ, Bai DS, Lee YH, Koo BH. Stress and Heart Rate Variability: A Meta-Analysis and Review of the Literature. Psychiatry Investig 2018;15:235=245. doi:10.30773/pi.2017.08.17. 
[128] Maheshwari A, Norby FL, Soliman EZ, Adabag S, Whitsel EA, Alonso A, et al. Low Heart Rate Variability in a 2-Minute Electrocardiogram Recording Is Associated with an Increased Risk of Sudden Cardiac Death in the General Population: The Atherosclerosis Risk in Communities Study. PLoS One 2016;11:e161648. doi:10.1371/journal.pone.0161648.

[129] Chang YM, Huang YT, Chen IL, Yang CL, Leu SC, Su HL, et al. Heart rate variability as an independent predictor for 8-year mortality among chronic hemodialysis patients. Sci Rep 2020;10:881. doi:10.1038/s41598-020-57792-3.

[130] Zhang D, Shen X, Qi X. Resting heart rate and all-cause and cardiovascular mortality in the general population: a meta-analysis. Can Med Assoc J 2016;188:E53-63. doi:10.1503/cmaj.150535.

[131] Prasada S, Oswalt C, Yeboah P, Saylor G, Bowden D, Yeboah J. Heart rate is an independent predictor of all-cause mortality in individuals with type 2 diabetes: The diabetes heart study. World J Diabetes 2018;9:33-9. doi:10.4239/wjd.v9.i1.33.

[132] Zhao Q, Li H, Wang A, Guo J, Yu J, Luo Y, et al. Cumulative Resting Heart Rate Exposure and Risk of All-Cause Mortality: Results from the Kailuan Cohort Study. Sci Rep 2017;7:40212. doi:10.1038/srep40212.

[133] Liu H, Liang Z, Cao N, Tan X, Liu Z, Wang F, et al. Airway bacterial and fungal microbiome in chronic obstructive pulmonary disease. BioRxiv 2020. doi:10.1101/2020.10.05.327536.

[134] Hoggard M, Mackenzie BW, Jain R, Taylor MW, Biswas K, Douglas RG. Chronic rhinosinusitis and the evolving understanding of microbial ecology in chronic inflammatory mucosal disease. Clin Microbiol Rev 2017;30:321-48. doi:10.1128/CMR.00060-16.

[135] Luca F De, Shoenfeld Y. The microbiome in autoimmune diseases. Clin Exp Immunol 2018. doi:10.1111/cei.13158.

[136] Stopinšek S, Ihan A, Salobir B, Terčelj M, Simčič S. Fungal cell wall agents and bacterial lipopolysaccharide in organic dust as possible risk factors for pulmonary sarcoidosis. J Occup Med Toxicol 2016;11:46. doi:10.1186/s12995-016-0135-4.

[137] Brownell I, Ramírez-Valle F, Sanchez M, Prystowsky S. Evidence for Mycobacteria in Sarcoidosis. Am J Respir Cell Mol Biol 2011;45:899-905. doi:10.1165/rcmb.2010-0433TR.

[138] Esteves T, Aparicio G, Garcia-Patos V. Is there any association between Sarcoidosis and infectious agents?: a systematic review and meta-analysis. BMC Pulm Med 2016;16:165. doi:10.1186/s12890-016-0332$\mathrm{z}$.

[139] Terčelj M, Salobir B, Zupancic M, Rylander R. Antifungal medication is efficient in the treatment of sarcoidosis. Ther Adv Respir Dis 2011;5:157-62. doi:10.1177/1753465811401648.

[140] Bachelez H, Senet P, Cadranel J, Kaoukhov A, Dubertret L. The Use of Tetracyclines for the Treatment of Sarcoidosis. Arch Dermatol 2001;137:69-73. doi:10.1001/archderm.137.1.69.

[141] Waterhouse JC, Perez TH, Albert PJ. Reversing bacteria-induced vitamin D receptor dysfunction is key to autoimmune disease. Ann N Y Acad Sci 2009;1173:757-65. doi:10.1111/j.1749-6632.2009.04637.x.

[142] Duréault A, Chapelon C, Biard L, Domont F, Savey L, Bodaghi B, et al. Severe infections in sarcoidosis: Incidence, predictors and long-term outcome in a cohort of 585 patients. Medicine (Baltimore) 2017;96:e8846. doi:10.1097/MD.0000000000008846.

[143] Rigottier-Gois L. Dysbiosis in inflammatory bowel diseases: the oxygen hypothesis microbe-microbe and microbe-host interactions. ISME J 2013;7:1256-61. doi:10.1038/ismej.2013.80.

[144] Rizzatti G, Lopetuso LR, Gibiino G, Binda C, Gasbarrini A. Proteobacteria: A common factor in human diseases. Biomed Res Int 2017;2017:1-7. doi:10.1155/2017/9351507. 
[145] Witkowski M, Witkowski M, Gagliani N, Huber S. Recipe for IBD: can we use food to control inflammatory bowel disease? The role of the immune system and the intestinal microbiota in IBD. Semin Immunopathol 2018;40:145-56. doi:10.1007/s00281-017-0658-5.

[146] Zhang M, Sun K, Wu Y, Yang Y, Tso P, Wu Z. Interactions between Intestinal Microbiota and Host Immune Response in Inflammatory Bowel Disease. Front Immunol 2017;8:942. doi:10.3389/fimmu.2017.00942.

[147] Agrawal G, Hamblin H, Clancy A, Borody T. Anti-Mycobacterial Antibiotic Therapy Induces Remission in Active Paediatric Crohn's Disease. Microorganisms 2020;8:1112. doi:10.3390/microorganisms8081112.

[148] Agrawal G, Clancy A, Huynh R, Borody T. Profound remission in Crohn's disease requiring no further treatment for 3-23 years: a case series. Gut Pathog 2020;12:16. doi:10.1186/s13099-020-00355-8.

[149] Agrawal G, Aitken J, Hamblin H, Collins M, Borody TJ. Putting Crohn's on the MAP: Five Common Questions on the Contribution of Mycobacterium avium subspecies paratuberculosis to the Pathophysiology of Crohn's Disease. Dig Dis Sci 2020:1-11. doi:10.1007/s10620-020-06653-0.

[150] Agrawal G, Borody T, Turner R, Leis S, Campbell J. Combining infliximab, anti-MAP and hyperbaric oxygen therapy for resistant fistulizing Crohn's disease. Futur Sci OA 2015;1:FSO77. doi:10.4155/fso.15.77.

[151] Agrawal G, Clancy A, Sharma R, Huynh R, Ramrakha S, Borody T. Targeted combination antibiotic therapy induces remission in treatment-naïve crohn's disease: A case series. Microorganisms 2020;8:371. doi:10.3390/microorganisms8030371.

[152] Dow CT, Sechi LA. Cows get crohn's disease and they're giving us diabetes. Microorganisms 2019;7. doi:10.3390/microorganisms7100466.

[153] National Advisory Committee on Microbiological Criteria. Assessment of Food as a Source of Exposure to Mycobacterium avium subspecies paratuberculosis (MAP). J Food Prot 2010;73:1357-97. doi:10.4315/0362-028x-73.7.1357.

[154] Sokol H, Leducq V, Aschard H, Pham HP, Jegou S, Landman C, et al. Fungal microbiota dysbiosis in IBD. Gut 2017;66:1039-48. doi:10.1136/gutjnl-2015-310746.

[155] Kotlyar DS, Shum M, Hsieh J, Blonski W, Greenwald DA. Non-pulmonary allergic diseases and inflammatory bowel disease: A qualitative review. World J Gastroenterol 2014;20:11023-32. doi:10.3748/wjg.v20.i32.11023.

[156] Gunasekeera V, Mendall MA, Chan D, Kumar D. Treatment of Crohn's Disease with an IgG4-Guided Exclusion Diet: A Randomized Controlled Trial. Dig Dis Sci 2016;61:1148-57. doi:10.1007/s10620-015-3987-z.

[157] Lee H, Lee JH, Koh SJ, Park H. Bidirectional relationship between atopic dermatitis and inflammatory bowel disease: a systematic review and meta-analysis. J Am Acad Dermatol 2020;93:1385-94. doi:10.1016/j.jaad.2020.05.130.

[158] Chudnow ML, Levy MB, Kelly KJ, Binion DG. Increased prevalence of environmental allergy in patients with Crohn's disease. J Allergy Clin Immunol 2004;113:S276. doi:10.1016/j.jaci.2004.01.468.

[159] Wasielewska Z, Dolińska A, Wilczyńska D, Szaflarska-Popławska A, Krogulska A. Prevalence of allergic diseases in children with inflammatory bowel disease. Postpy Dermatol Alergol 2019;36:282-90. doi:10.5114/ada.2018.81189.

[160] Sun Y, Li L, Xie R, Wang B, Jiang K, Cao H. Stress Triggers Flare of Inflammatory Bowel Disease in Children and Adults. Front Pediatr 2019;7:432. doi:10.3389/fped.2019.00432.

[161] Mawdsley JE, Rampton DS. Psychological stress in IBD: new insights into pathogenic and therapeutic implications. Gut 2005;54:1481-91. doi:10.1136/gut.2005.064261. 
[162] Brassard P, Vutcovici M, Ernst P, Patenaude V, Sewitch M, Suissa S, et al. Increased incidence of inflammatory bowel disease in Québec residents with airway diseases. Eur Respir J 2015;45:962-8. doi:10.1183/09031936.00079414.

[163] Gómez-Gascón L, Bröker BM. Bacterial Allergens. In: Schmidt-Weber CB, editor. Allergy Prev. Exacerbation, Springer International Publishing; 2017, p. 27-50. doi:10.1007/978-3-319-69968-4_3.

[164] Nordengrün M, Michalik S, Völker U, Bröker BM, Gómez-Gascón L. The quest for bacterial allergens. Int J Med Microbiol 2018;308:738-50. doi:10.1016/j.ijmm.2018.04.003.

[165] Dutkiewicz J, Mackiewicz B, Lemieszek MK, Golec M, Skórska C, Góra-Florek A, et al. Pantoea agglomerans: a mysterious bacterium of evil and good. Part II - Deleterious effects: Dust- borne endotoxins and allergens - focus on grain dust, other agricultural dusts and wood dust. Ann Agric Env Med 2016;23:6-29. doi:10.5604/12321966.1196848.

[166] Lecours PB, Veillette M, Marsolais D, Duchaine C. Characterization of Bioaerosols from Dairy Barns: Reconstructing the Puzzle of Occupational Respiratory Diseases by Using Molecular Approaches. Appl Environ Microbiol 2012;78:3242-8. doi:10.1128/AEM.07661-11.

[167] Lecours PB, Duchaine C, Taillefer M, Tremblay C, Veillette M, Cormier Y, et al. Immunogenic Properties of Archaeal Species Found in Bioaerosols. PLoS One 2011;6:e23326. doi:10.1371/journal.pone.0023326.

[168] Smith-Norowitz TA, Josekutty J, Lev-Tov H, Kohlhoff S, Norowitz KB, Silverberg JI, et al. IgE AntiVaricella Zoster Virus and Other Immune Responses Before, During, and After Shingles. Ann Clin Lab Sci 2009;39:43-50.

[169] Smith-Norowitz TA, Josekutty J, Silverberg JI, Lev-Tov H, Norowitz YM, Kohlhoff S, et al. Long Term Persistence of IgE Anti-Varicella Zoster Virus in Pediatric and Adult Serum Post Chicken Pox Infection and after Vaccination with Varicella Virus Vaccine. Int J Biomed Sci 2009;5:353-8. doi:10.1016/j.jaci.2007.12.770.

[170] Smith-Norowitz TA, Wong D, Kusonruksa M, Norowitz KB, Joks R, Durkin HG, et al. Long Term Persistence of IgE Anti-Influenza Virus Antibodies in Pediatric and Adult Serum Post Vaccination with Influenza Virus Vaccine. Int J Med Sci 2011;8:239-44. doi:10.7150/ijms.8.239.

[171] Smith-Norowitz TA, Drew H, Norowitz HM, Nowakowski M, Bluth EF, Durkin HG, et al. Detection of IgE Anti-Parvovirus Antibodies in Human Breast Milk. Ann Clin Lab Sci 2008;38:168-73.

[172] Bachert C, Pawankar R, Zhang L, Bunnag C, Fokkens WJ, Hamilos DL, et al. ICON: chronic rhinosinusitis. World Allergy Organ J 2014;7:25. doi:10.1186/1939-4551-7-25.

[173] Calenoff E, McMahan JT, Herzon GD, Kern RC, Ghadge GD, Hanson DG. Bacterial Allergy in Nasal Polyposis A New Method for Quantifying Specific IgE. Arch Otolaryngol Neck Surg 1993;119:830-6. doi:10.1001/archotol.1993.01880200030004.

[174] Mendell MJ, Mirer AG, Cheung K, Tong M, Douwes J. Respiratory and Allergic Health Effects of Dampness, Mold, and Dampness-Related Agents: A Review of the Epidemiologic Evidence. Environ Health Perspect 2011;119:748-56. doi:10.1289/ehp.1002410.

[175] Park J-H, Cox-Ganser JM, White SK, Laney AS, Caulfield SM, Turner WA, et al. Bacteria in a waterdamaged building: associations of actinomycetes and non-tuberculous mycobacteria with respiratory health in occupants. Indoor Air 2017;27:24-33. doi:10.1111/ina.12278.

[176] Huttunen K, Hyvärinen A, Nevalainen A, Komulainen H, Hirvonen M-R. Production of Proinflammatory Mediators by Indoor Air Bacteria and Fungal Spores in Mouse and Human Cell Lines. Environ Health Perspect 2003;111:85-92. doi:10.1289/ehp.5478.

[177] Feazel LM, Baumgartner LK, Peterson KL, Frank DN, Harris JK, Pace NR. Opportunistic pathogens enriched in showerhead biofilms. Proc Natl Acad Sci U S A 2009;106:16393-9. doi:10.1073/pnas.0908446106. 
[178] Nogaller AM, Maligin AG. Specific bacterial immunotherapy in chronic colitis. Allergol Immunopathol (Madr) 1980;9:9-18.

[179] Bacigaluppi JE, Negroni R, de Severino HM. Bacterial allergy in allergic rhinitis and bronchial asthma. Ann Allergy 1979;42:95-8.

[180] Oehling A, Baena-Cagnani C, Neffen H. Bacterial immunotherapy of childhood bronchial asthma. Allergol Immunopathol (Madr) 1980;8:177-84.

[181] Malling HJ. Bacterial vaccines: anything but placebo. Allergy 2000;55:214-8. doi:10.1034/j.13989995.2000.00110.x.

[182] Zak-Nejmark T, Małolepszy J, Kraus-Filarska M, Nadobna G, Jutel M, Stankiewicz M. Autologous bacteria induce chemotaxis of peripheral blood mononuclear cells (MNC) from non-atopic asthmatics. Clin Exp Allergy 1992;22:863-6. doi:10.1111/j.1365-2222.1992.tb02832.x.

[183] Matricardi PM, Bjorksten B, Bousquet J, Diukanovic R, Dreborg S, Gereda J, et al. Microbial products in allergy prevention and therapy. Allergy 2003;58:461-71. doi:10.1034/j.1398-9995.2003.00175.x.

[184] Vasakova M, Morell F, Walsh S, Leslie K, Raghu G. Hypersensitivity Pneumonitis: Perspectives in Diagnosis and Management. Am J Respir Crit Care Med 2017;196:680-9. doi:10.1164/rccm.201611-2201PP.

[185] Seaman DM, Meyer CA, Kanne JP. Occupational and Environmental Lung Disease. Clin Chest Med 2015;36:249-68. doi:10.1016/j.ccm.2015.02.008.

[186] Quirce S, Vandenplas O, Campo P, Cruz MJ, de Blay F, Koschel D, et al. Occupational hypersensitivity pneumonitis: an EAACI position paper. Allergy 2016;71:765-79. doi:10.1111/all.12866.

[187] Riario Sforza GG, Marinou A. Hypersensitivity pneumonitis: a complex lung disease. Clin Mol Allergy 2017;15:6. doi:10.1186/s12948-017-0062-7.

[188] Horve PF, Lloyd S, Mhuireach GA, Dietz L, Fretz M, MacCrone G, et al. Building upon current knowledge and techniques of indoor microbiology to construct the next era of theory into microorganisms, health, and the built environment. J Expo Sci Env Epidemiol 2019;30:219-35. doi:10.1038/s41370-019-0157y.

[189] Gilbert JA, Stephens B. Microbiology of the built environment. Nat Rev Microbiol 2018;16:661-670. doi:10.1038/s41579-018-0065-5.

[190] Jiang C, Wang X, Li X, Inlora J, Wang T, Liu Q, et al. Dynamic Human Environmental Exposome Revealed by Longitudinal Personal Monitoring. Cell 2018;175:277-291.e31. doi:10.1016/j.cell.2018.08.060.

[191] Stinson LF, Keelan JA, Payne MS. Identification and removal of contaminating microbial DNA from PCR reagents: impact on low-biomass microbiome analyses. Lett Appl Microbiol 2019;68:2-8. doi:10.1111/lam.13091.

[192] Ruemmele FM. Role of Diet in Inflammatory Bowel Disease. Ann Nutr Metab 2016;68:33-41. doi: $10.1159 / 000445392$.

[193] Naja F, Hwalla N, Itani L, Karam S, Sibai AM, Nasreddine L. A Western dietary pattern is associated with overweight and obesity in a national sample of Lebanese adolescents (13-19 years): a cross-sectional study. Br j Nutr 2015;114:1909-19. doi:10.1017/S0007114515003657.

[194] Trott S, King IL. An introduction to the microbiome and MS. Mult Scler 2018;24:53-7. doi:10.1177/1352458517737391.

[195] Benchimol EI, Manuel DG, To T, Mack DR, Nguyen GC, Gommerman JL, et al. Asthma, type 1 and type 2 diabetes mellitus, and inflammatory bowel disease amongst South Asian immigrants to Canada and their children: a population-based cohort study. PLoS One 2015;10:e0123599. doi:10.1371/journal.pone.0123599. 
[196] Poongadan MN, Gupta N, Kumar R. Dietary pattern and asthma in India. Pneumonol Alergol Pol 2016;84:160-7. doi:10.5603/PiAP.2016.0018.

[197] Chiba M, Ishii H, Komatsu M. Recommendation of plant-based diets for inflammatory bowel disease. Transl Pediatr 2019;8:23-7. doi:10.21037/tp.2018.12.02.

[198] Nazarenkov N, Seeger K, Beeken L, Ananthakrishnan AN, Khalili H, Lewis JD, et al. Implementing Dietary Modifications and Assessing Nutritional Adequacy of Diets for Inflammatory Bowel Disease. Gastroenterol Hepatol (N Y) 2019;15:133-44.

[199] Levine A, Wine E, Assa A, Sigall Boneh R, Shaoul R, Kori M, et al. Crohn's Disease Exclusion Diet Plus Partial Enteral Nutrition Induces Sustained Remission in a Randomized Controlled Trial. Gastroenterology 2019;157:440-450.e8. doi:10.1053/j.gastro.2019.04.021.

[200] Spellberg B, Hansen GR, Kar A, Cordova CD, Price LB, Johnson JR. Antibiotic Resistance in Humans and Animals. NAM Perspect 2016;6. doi:10.31478/201606d.

[201] Lindahl O, Lindwall L, Spångberg A, Stenram Å, Öckerman PA. Vegan Regimen with Reduced Medication in the Treatment of Bronchial Asthma. J Asthma 1985;22:45-55. doi:10.3109/02770908509079883.

[202] Haugen M, Kjeldsen-Kragh J, Nordvåg BY, Førre O. Diet and disease symptoms in rheumatic diseasesresults of a questionnaire based survey. Clin Rheumatol 1991;10:401-7. doi:10.1007/bf02206660.

[203] McDougall J, Bruce B, Spiller G, Westerdahl J, McDougall M. Effects of a Very LowFat, Vegan Diet in Subjects with Rheumatoid Arthritis. J Altern Complement Med 2002;8:71-5. doi:10.1089/107555302753507195.

[204] Trichopoulou A, Bamia C, Trichopoulos D. Anatomy of health effects of Mediterranean diet: Greek EPIC prospective cohort study. BMJ 2009;338:b2337. doi:10.1136/bmj.b2337.

[205] Davinelli S, Willcox DC, Scapagnini G. Extending healthy ageing: nutrient sensitive pathway and centenarian population. Immun Ageing 2012;9:9. doi:10.1186/1742-4933-9-9.

[206] Prenafeta-Boldú FX, Summerbell R, de Hoog GS. Fungi growing on aromatic hydrocarbons: Biotechnology's unexpected encounter with biohazard? FEMS Microbiol Rev 2006;30:109-30. doi:10.1111/j.15746976.2005.00007.x.

[207] Massier L, Chakaroun R, Tabei S, Crane A, David Didt K, Fallmann J, et al. Adipose tissue derived bacteria are associated with inflammation in obesity and type 2 diabetes. Gut 2020;69:1796-806. doi:10.1136/gutjnl-2019-320118.

[208] Chakaroun RM, Massier L, Kovacs P. Gut Microbiome, Intestinal Permeability, and Tissue Bacteria in Metabolic Disease: Perpetrators or Bystanders? Nutrients 2020;12:1082. doi:10.3390/nu12041082.

[209] Jensen BA, Marette A. Microbial translocation in type 2 diabetes: when bacterial invaders overcome host defence in human obesity. Gut 2020;69:1724-6. doi:10.1136/gutjnl-2020-321288.

[210] Ornish D, Brown SE, Scherwitz LW, Billings JH, Armstrong WT, Ports TA, et al. Can lifestyle changes reverse coronary heart disease? The Lifestyle Heart Trial. Lancet 1990;336:129-33. doi:10.1016/01406736(90)91656-u.

[211] Ornish D. Avoiding revascularization with lifestyle changes: The Multicenter Lifestyle Demonstration Project. Am J Cardiol 1998;82:72T-76T. doi:10.1016/s0002-9149(98)00744-9.

[212] Swank RL. Multiple Sclerosis: Twenty Years on Low Fat Diet. Arch Neurol 1970;23:460-74. doi:10.1001/archneur.1970.00480290080009.

[213] Wahls TL, Chenard CA, Snetselaar LG. Review of Two Popular Eating Plans within the Multiple Sclerosis Community: Low Saturated Fat and Modified Paleolithic. Nutrients 2019;11:352. doi:10.3390/nu11020352. 
[214] Drago S, El Asmar R, Di Pierro M, Grazia Clemente M, Tripathi A, Sapone A, et al. Gliadin, zonulin and gut permeability: Effects on celiac and non-celiac intestinal mucosa and intestinal cell lines. Scand J Gastroenterol 2006;41:408-19. doi:10.1080/00365520500235334.

[215] Fasano A. All disease begins in the (leaky) gut: role of zonulin-mediated gut permeability in the pathogenesis of some chronic inflammatory diseases. F1000Research 2020;9:F1000 Faculty. doi:10.12688/f1000research.20510.1.

[216] Mu Q, Kirby J, Reilly CM, Luo XM. Leaky Gut As a Danger Signal for Autoimmune Diseases. Front Immunol 2017;8:598. doi:10.3389/fimmu.2017.00598.

[217] Keller KB, Lemberg L. Obesity and the metabolic syndrome. Am J Crit Care 2003;12:167-70.

[218] Kankaanranta H, Kauppi P, Tuomisto LE, Ilmarinen P. Emerging Comorbidities in Adult Asthma: Risks, Clinical Associations, and Mechanisms. Mediators Inflamm 2016;2016:3690628. doi:10.1155/2016/3690628.

[219] Lokaj-Berisha V, Gacaferri-Lumezi B, Minci-Bejtullahu G, Latifi-Pupovci H, Karahoda-Gjurgjeala N, Berisha N, et al. Gender Associated High Body Mass Index in Allergic Diseases. Maced J Med Sci 2015;3:6974. doi:10.3889/oamjms.2015.008.

[220] Chung S-D, Chen P-Y, Lin H-C, Hung S-H. Comorbidity profile of chronic rhinosinusitis: a populationbased study. Laryngoscope 2014;124:1536-41. doi:10.1002/lary.24581.

[221] Gremese E, Tolusso B, Gigante MR, Ferraccioli G. Obesity as a Risk and Severity Factor in Rheumatic Diseases (Autoimmune Chronic Inflammatory Diseases). Front Immunol 2014;5:576. doi:10.3389/fimmu.2014.00576.

[222] Versini M, Jeandel P-Y, Rosenthal E, Shoenfeld Y. Obesity in autoimmune diseases: Not a passive bystander. Autoimmun Rev 2014;13:981-1000. doi:10.1016/j.autrev.2014.07.001.

[223] Hu T, Mills KT, Yao L, Demanelis K, Eloustaz M, Yancy WS, et al. Effects of Low-Carbohydrate Diets Versus Low-Fat Diets on Metabolic Risk Factors: A Meta-Analysis of Randomized Controlled Clinical Trials. Am J Epidemiol 2012;176:S44-54. doi:10.1093/aje/kws264.

[224] Gardner CD, Trepanowski JF, Del Gobbo LC, Hauser ME, Rigdon J, Ioannidis JPA, et al. Effect of LowFat vs Low-Carbohydrate Diet on 12-Month Weight Loss in Overweight Adults and the Association With Genotype Pattern or Insulin Secretion: The DIETFITS Randomized Clinical Trial. JAMA 2018;319:667-79. doi:10.1001/jama.2018.0245.

[225] Zeevi D, Korem T, Zmora N, Israeli D, Rothschild D, Weinberger A, et al. Personalized Nutrition by Prediction of Glycemic Responses. Cell 2015;163:1079-94. doi:10.1016/j.cell.2015.11.001.

[226] Li L, Li X, Zhou W, Messina JL. Acute Psychological Stress Results in the Rapid Development of Insulin Resistance. J Endocrinol 2013;217:175-84. doi:10.1530/JOE-12-0559.

[227] Sade MY, Kloog I, Liberty IF, Katra I, Novack L, Novack V. Air Pollution and Serum Glucose Levels: A Population-Based Study. Medicine (Baltimore) 2015;94:e1093. doi:10.1097/MD.0000000000001093.

[228] Park SK. Ambient Air Pollution and Type 2 Diabetes: Do the Metabolic Effects of Air Pollution Start Early in Life? Diabetes 2017;66:1755-7. doi:10.2337/dbi17-0012.

[229] Eze IC, Hemkens LG, Bucher HC, Hoffmann B, Schindler C, Künzli N, et al. Association between Ambient Air Pollution and Diabetes Mellitus in Europe and North America: Systematic Review and MetaAnalysis. Environ Health Perspect 2015;123:381-9. doi:10.1289/ehp.1307823.

[230] Hall KD, Ayuketah A, Brychta R, Cai H, Cassimatis T, Chen KY, et al. Ultra-Processed Diets Cause Excess Calorie Intake and Weight Gain: An Inpatient Randomized Controlled Trial of Ad Libitum Food 
Intake Cell Metabolism Clinical and Translational Report Ultra-Processed Diets Cause Excess Ca. Cell Metab 2019;30:67-77.e3. doi:10.1016/j.cmet.2019.05.008.

[231] Alcock J, Maley CC, Aktipis CA. Is eating behavior manipulated by the gastrointestinal microbiota? Evolutionary pressures and potential mechanisms. Bioessays 2014;36:940-9. doi:10.1002/bies.201400071.

[232] Schulte EM, Avena NM, Gearhardt AN. Which Foods May Be Addictive? The Roles of Processing, Fat Content, and Glycemic Load. PLoS One 2015;10:e0117959. doi:10.1371/journal.pone.0117959.

[233] Konijeti GG, Kim N, Lewis JD, Groven S, Chandrasekaran A, Grandhe S, et al. Efficacy of the Autoimmune Protocol Diet for Inflammatory Bowel Disease. Inflamm Bowel Dis 2017;23:2054-60. doi:10.1097/MIB.0000000000001221.

[234] Abbott RD, Sadowski A, Alt AG. Efficacy of the Autoimmune Protocol Diet as Part of a Multi-disciplinary, Supported Lifestyle Intervention for Hashimoto's Thyroiditis. Cureus 2019;11:e4556. doi:10.7759/cureus.4556.

[235] Irish AK, Erickson CM, Wahls TL, Snetselaar LG, Darling WG. Randomized control trial evaluation of a modified Paleolithic dietary intervention in the treatment of relapsing-remitting multiple sclerosis: a pilot study. Degener Neurol Neuromuscul Dis 2017;7:1-18. doi:10.2147/DNND.S116949.

[236] Gupta L, Khandelwal D, Lal PR, Kalra S, Dutta D. Palaeolithic Diet in Diabesity and Endocrinopathies - A Vegan's Perspective. Eur Endocrinol 2019;15:77-82. doi:10.17925/EE.2019.15.2.77.

[237] Fakih R, Diaz-Cruz C, Chua AS, Gonzalez C, Healy BC, Sattarnezhad N, et al. Food allergies are associated with increased disease activity in multiple sclerosis. J Neurol Neurosurg Psychiatry 2019;90:62935. doi:10.1136/jnnp-2018-319301.

[238] Farez MF. Food allergies and multiple sclerosis. J Neurol Neurosurg Psychiatry 2019;90:625. doi:10.1136/jnnp-2018-319585.

[239] Karatay S, Erdem T, Yildirim K, Melikoglu MA, Ugur M, Cakir E, et al. The effect of individualized diet challenges consisting of allergenic foods on TNF-alpha and IL-1beta levels in patients with rheumatoid arthritis. Rheumatology (Oxford) 2004;43:1429-33. doi:10.1093/rheumatology/keh366.

[240] Yu KK, Crew AB, Messingham KA, Fairley JA, Woodley DT. Omalizumab therapy for bullous pemphigoid. J Am Acad Dermatol 2014;71:468-74. doi:10.1016/j.jaad.2014.04.053.

[241] Al-Ahmad M. Omalizumab therapy in three patients with chronic autoimmune urticaria. Ann Saudi Med 2010;30:478-81. doi:10.4103/0256-4947.70567.

[242] Hasni S, Gupta S, Davis M, Poncio E, Temesgen-Oyelakin Y, Joyal E, et al. Safety and Tolerability of Omalizumab: A Randomized Clinical Trial of Humanized Anti-IgE Monoclonal Antibody in Systemic Lupus Erythematosus. Arthritis Rheumatol 2019;71:1135-40. doi:10.1002/art.40828.

[243] Lin L, Moran TP, Peng B, Yang J, Culton DA, Che H, et al. Walnut antigens can trigger autoantibody development in patients with pemphigus vulgaris through a "hit-and-run" mechanism. J Allergy Clin Immunol 2019;144:720-728.e4. doi:10.1016/j.jaci.2019.04.020.

[244] Hvatum M, Kanerud L, Hallgren R, Brandtzaeg P. The gut-joint axis: cross reactive food antibodies in rheumatoid arthritis. Gut 2006;55:1240-7. doi:10.1136/gut.2005.076901.

[245] Jethwa H, Prince M, Bukhari M, Abraham S. The evidence for dietary manipulation in inflammatory arthritis. Int J Clin Rheumtol 2019;14:190-9.

[246] Hemmings O, Kwok M, McKendry R, Santos AF. Basophil Activation Test: Old and New Applications in Allergy. Curr Allergy Asthma Rep 2018;18:77. doi:10.1007/s11882-018-0831-5.

[247] Eguiluz-Gracia I, Perez-Sanchez N, Bogas G, Campo P, Rondon C. How to Diagnose and Treat Local Allergic Rhinitis: A Challenge for Clinicians. J Clin Med 2019;8:1062. doi:10.3390/jcm8071062. 
[248] Cozma-Petrut A, Loghin F, Miere D, Dumitraşcu DL. Diet in irritable bowel syndrome: What to recommend, not what to forbid to patients! World J Gastroenterol 2017;23:3771-83. doi:10.3748/wjg.v23.i21.3771.

[249] Fang Z-Y, Zhang H-T, Lu C, Lu Q-M, Yu C-H, Wang H-Y. Association between Allergic Diseases and Irritable Bowel Syndrome: A Retrospective Study. Int Arch Allergy Immunol 2018;177:153-9. doi:10.1159/000489611.

[250] Koloski N, Jones M, Walker MM, Veysey M, Zala A, Keely S, et al. Population based study: atopy and autoimmune diseases are associated with functional dyspepsia and irritable bowel syndrome, independent of psychological distress. Aliment Pharmacol Ther 2019;49:546-55. doi:10.1111/apt.15120.

[251] Ford AC, Talley NJ, Walker MM, Jones MP. Increased prevalence of autoimmune diseases in functional gastrointestinal disorders: case-control study of 23471 primary care patients. Aliment Pharmacol Ther 2014;40:827-34. doi:10.1111/apt.12903.

[252] Farup PG, Ueland T, Rudi K, Lydersen S, Hestad K. Functional Bowel Disorders Are Associated with a Central Immune Activation. Gastroenterol Res Pract 2017;2017:1642912. doi:10.1155/2017/1642912.

[253] Lee KN, Lee OY. The Role of Mast Cells in Irritable Bowel Syndrome. Gastroenterol Res Pract 2016;2016:2031480. doi:10.1155/2016/2031480.

[254] Werlang ME, Palmer WC, Lacy BE. Irritable Bowel Syndrome and Dietary Interventions. Gastroenterol Hepatol (N Y) 2019;15:16-26.

[255] Ali A, Weiss TR, McKee D, Scherban A, Khan S, Fields MR, et al. Efficacy of individualised diets in patients with irritable bowel syndrome: a randomised controlled trial. BMJ Open Gastroenterol 2017;4:e000164. doi:10.1136/BMJGAST-2017-000164.

[256] Garcia-Martinez I, Weiss TR, Yousaf MN, Ali A, Mehal WZ. A leukocyte activation test identifies food items which induce release of DNA by innate immune peripheral blood leucocytes. Nutr Metab 2018;15:26. doi:10.1186/s12986-018-0260-4.

[257] Lukaszuk JM, Shokrani M, Roy PG, Hoppensteadt J, Umoren J. Effects of Antigen Leukocyte Cellular Activation Test-Based Diet on Inflammation, Body Composition, and Medical Symptoms. Altern Complem Ther 2018;24:215-21. doi:10.1089/act.2018.29183.jml.

[258] Fritscher-Ravens A, Schuppan D, Ellrichmann M, Schoch S, Röcken C, Brasch J, et al. Confocal Endomicroscopy Shows Food-Associated Changes in the Intestinal Mucosa of Patients With Irritable Bowel Syndrome. Gastroenterology 2014;147:1012-1020.e4. doi:10.1053/j.gastro.2014.07.046.

[259] Lee HS, Lee KJ. Immunoglobulin G4-related immune responses to common food antigens in patients with ulcerative colitis and Crohn's disease. Turkish J Gastroenterol 2019;30:408-14. doi:10.5152/tjg.2019.18466.

[260] Wright BL, Kulis M, Guo R, Orgel KA, Wolf WA, Burks AW, et al. Food-specific IgG4 is associated with eosinophilic esophagitis. J Allergy Clin Immunol 2016;138:1190-1192.e3. doi:10.1016/j.jaci.2016.02.024.

[261] Rosenberg CE, Mingler MK, Caldwell JM, Collins MH, Fulkerson PC, Morris DW, et al. Esophageal IgG4 levels correlate with histopathologic and transcriptomic features in eosinophilic esophagitis. Allergy 2018;73:1892-901. doi:10.1111/all.13486.

[262] Gocki J, Bartuzi Z. Role of immunoglobulin G antibodies in diagnosis of food allergy. Postep Dermatol Alergol 2016;33:253-6. doi:10.5114/ada.2016.61600.

[263] Bianchini R, Karagiannis SN, Jordakieva G, Jensen-Jarolim E. The role of IgG4 in the fine tuning of tolerance in IgE-mediated allergy and cancer. Int J Mol Sci 2020;21:1507. doi:10.3390/ijms21145017.

[264] Moss RB, Carmack MA, Esrig S. Deficiency of IgG4 in children: Association of isolated IgG4 deficiency with recurrent respiratory tract infection. J Pediatr 1992;120:16-21. doi:10.1016/s0022-3476(05)80590-6. 
[265] Dine G, Ali-Ammar N, Brahimi S, Rehn Y. Chronic sinusitis in a patient with selective IgG4 subclass deficiency controlled with enriched immunoglobulins. Clin Case Reports 2017;5:792-4. doi:10.1002/ccr3.936.

[266] Ryu JH, Horie R, Sekiguchi H, Peikert T, Yi ES. Spectrum of Disorders Associated with Elevated Serum IgG4 Levels Encountered in Clinical Practice. Int J Rheumatol 2012;2012:232960. doi:10.1155/2012/232960.

[267] Trampert DC, Hubers LM, van de Graaf SFJ, Beuers U. On the role of IgG4 in inflammatory conditions: lessons for IgG4-related disease. Biochim Biophys Acta Mol Basis Dis 2018;1864:1401-9. doi:10.1016/j.bbadis.2017.07.038.

[268] Hsieh SC, Shen CY, Liao HT, Chen MH, Wu CH, Li KJ, et al. The Cellular and Molecular Bases of Allergy, Inflammation and Tissue Fibrosis in Patients with IgG4-related Disease. Int J Mol Sci 2020;21:5082. doi:10.3390/ijms21145082.

[269] Culver EL, van de Bovenkamp FS, Derksen NIL, Koers J, Cargill T, Barnes E, et al. Unique patterns of glycosylation in immunoglobulin subclass G4-related disease and primary sclerosing cholangitis. J Gastroenterol Hepatol 2019;34:1878-86. doi:10.1111/jgh.14512.

[270] Toorenenbergen AW Van, Heerde MJ Van, Buuren HR Van. Potential Value of Serum Total IgE for Differentiation between Autoimmune Pancreatitis and Pancreatic Cancer. Scand J Immunol 2010;72:444-8. doi:10.1111/j.1365-3083.2010.02453.x.

[271] Culver EL, Vermeulen E, Makuch M, van Leeuwen A, Sadler R, Cargill T, et al. Increased IgG4 responses to multiple food and animal antigens indicate a polyclonal expansion and differentiation of preexisting B cells in IgG4-related disease. Ann Rheum Dis 2015;74:944-7. doi:10.1136/annrheumdis-2014206405.

[272] de Buy Wenniger LJ, Culver EL, Beuers U. Exposure to occupational antigens might predispose to IgG4-related disease. Hepatology 2014;60:1453=1454. doi:10.1002/hep.26999.

[273] Harrison SL, Fazio-Eynullayeva E, Lane DA, Underhill P, Lip GYH. Comorbidities associated with mortality in 31,461 adults with COVID-19 in the United States: A federated electronic medical record analysis. PLOS Med 2020;17:e1003321. doi:10.1371/journal.pmed.1003321.

[274] Waterhouse J. Exploring the microbiome's potential role in severe COVID-19: possible implications for prevention and treatment. Authorea Prepr 2020. doi:10.22541/au.158758665.58622495.

[275] Koren O, Spor A, Felin J, Fak F, Stombaugh J, Tremaroli V, et al. Human oral, gut, and plaque microbiota in patients with atherosclerosis. Proc Natl Acad Sci U S A 2011;108:4592-8. doi:10.1073/pnas.1011383107.

[276] Burcelin R. Gut microbiota and immune crosstalk in metabolic disease. Mol Metab 2016;5:771-81. doi:10.1016/j.molmet.2016.05.016.

[277] Woodruff MC, Ramonell RP, Lee FE-H, Sanz I. Clinically identifiable autoreactivity is common in severe SARS-CoV-2 Infection. MedRxiv 2020. doi:10.1101/2020.10.21.20216192.

[278] Theoharides TC. COVID-19, pulmonary mast cells, cytokine storms, and beneficial actions of luteolin. Biofactors 2020;46:306-8. doi:10.1002/biof.1633.

[279] Kempuraj D, Selvakumar GP, Ahmed ME, Raikwar SP, Thangavel R, Khan A, et al. COVID-19, Mast Cells, Cytokine Storm, Psychological Stress, and Neuroinflammation. Neurosci 2020;26:402-414. doi:10.1177/1073858420941476.

[280] Hogan II RB, Hogan III RB, Cannon T, Rappai M, Studdard J, Paul D, et al. Dual-histamine receptor blockade with cetirizine - famotidine reduces pulmonary symptoms in COVID-19 patients. Pulm Pharmacol Ther 2020;63:101942. doi:10.1016/j.pupt.2020.101942. 
[281] Rogosnitzky M, Berkowitz E, Jadad AR. No Time to Waste: Real-World Repurposing of Generic Drugs as a Multifaceted Strategy Against COVID-19. JMIRx | Med 2020;1:e19583. doi:10.2196/19583.

[282] Malone RW, Tisdall P, Fremont-Smith P, Liu Y, Huang X-P, White KM, et al. COVID-19: Famotidine, Histamine, Mast Cells, and Mechanisms. Prepr Res Sq 2020;Version 2:rs.3.rs-30934. doi:10.21203/rs.3.rs$30934 / \mathrm{v} 2$.

[283] Andersson CK, Mori M, Bjermer L, Lofdahl C-G, Erjefalt JS. Alterations in Lung Mast Cell Populations in Patients with Chronic Obstructive Pulmonary Disease. Am J Respir Crit Care Med 2010;181:206-17. doi:10.1164/rccm.200906-0932OC.

[284] Xu Y, Chen G. Mast Cell and Autoimmune Diseases. Mediators Inflamm 2015;2015:246126. doi:10.1155/2015/246126.

[285] Magrone T, Magrone M, Jirillo E. Mast Cells as A Double Edged Sword in Immunity: Disorders of Mast Cell Activation and Therapeutic Management. Second of Two Parts. Endocrine, Metab Immune Disord - Drug Targets 2019;19. doi:10.2174/1871530319666191202121644.

[286] Jin JM, Sun YC. Allergy and Chronic Obstructive Pulmonary Disease. Chinese Med J 2017;130:201720. doi:10.4103/0366-6999.213427.

[287] Tzortzaki EG, Proklou A, Siafakas NM. Asthma in the Elderly: Can We Distinguish It from COPD? J Allergy 2011;2011:1-7. doi:10.1155/2011/843543.

[288] To T, Zhu J, Larsen K, Simatovic J, Feldman L, Ryckman K, et al. Progression from Asthma to Chronic Obstructive Pulmonary Disease. Is Air Pollution a Risk Factor? Am J Respir Crit Care Med 2016;194:429-38. doi:10.1164/rccm.201510-1932OC.

[289] Veil-Picard M, Soumagne T, Vongthilath R, Annesi-Maesano I, Guillien A, Laurent L, et al. Is atopy a risk indicator of chronic obstructive pulmonary disease in dairy farmers? Respir Res 2019;20:124. doi:10.1186/s12931-019-1082-2.

[290] Vaz Fragoso C, Murphy T, Agogo G, Allore H, McAvay G. Asthma-COPD overlap syndrome in the US: a prospective population-based analysis of patient-reported outcomes and health care utilization. Int J Chron Obstruct Pulmon Dis 2017;12:517-27. doi:10.2147/COPD.S121223.

[291] Jaakkola MS, Lajunen TK, Jaakkola JJK. Indoor mold odor in the workplace increases the risk of Asthma-COPD Overlap Syndrome: a population-based incident case-control study. Clin Transl Allergy 2020;10:3. doi:10.1186/s13601-019-0307-2.

[292] Rossi A, Butorac-Petanjek B, Chilosi M, Cosio BG, Flezar M, Koulouris N, et al. Chronic obstructive pulmonary disease with mild airflow limitation: Current knowledge and proposal for future research - A consensus document from six scientific societies. Int J COPD 2017;12:2593-610. doi:10.2147/COPD.S132236.

[293] De Schryver E, Devuyst L, Derycke L, Dullaers M, Van Zele T, Bachert C, et al. Local Immunoglobulin E in the Nasal Mucosa: Clinical Implications. Allergy Asthma Immunol Res 2015;7:321-31. doi:10.4168/aair.2015.7.4.321.

[294] Perelmutter L, Potvin L, Phipps P. Immunoglobulin E response during viral infections. J Allergy Clin Immunol 1979;64:127-30. doi:10.1016/0091-6749(79)90046-0.

[295] Lommatzsch M, Stoll P, Virchow JC. COVID-19 in a patient with severe asthma treated with Omalizumab. Allergy 2020;75:2705-8. doi:10.1111/all.14456.

[296] Esquivel A, Busse WW, Calatroni A, Togias AG, Grindle KG, Bochkov YA, et al. Effects of Omalizumab on Rhinovirus Infections, Illnesses, and Exacerbations of Asthma. Am J Respir Crit Care Med 2017;196:985. doi:10.1164/rccm.201701-0120OC. 
[297] Vaughn VM, Gandhi T, Petty LA, Patel PK, Prescott HC, Malani AN, et al. Empiric Antibacterial Therapy and Community-onset Bacterial Co-infection in Patients Hospitalized with COVID-19: A MultiHospital Cohort Study. Clin Infect Dis 2020;21:ciaa1239. doi:10.1093/cid/ciaa1239.

[298] Zhou P, Liu Z, Chen Y, Xiao Y, Huang X, Fan XG. Bacterial and fungal infections in COVID-19 patients: A matter of concern. Infect Control Hosp Epidemiol 2020;41:1124-1125. doi:10.1017/ice.2020.156.

[299] Arunachalam PS, Wimmers F, Mok CKP, Perera RAPM, Scott M, Hagan T, et al. Systems biological assessment of immunity to mild versus severe COVID-19 infection in humans. Science 2020;369:1210-20. doi:10.1126/science.abc6261.

[300] Rawson TM, Wilson RC, Holmes A. Understanding the role of bacterial and fungal infection in COVID19. Clin Microbiol Infect 2020:S1198. doi:10.1016/j.cmi.2020.09.025.

[301] Chen Y, Dong Y, Cai S, Ye C, Dong L. Clinical characteristics of IgG4-RD patients infected with COVID-19 in Hubei, China. Semin Arthritis Rheum 2020;50:559-63. doi:10.1016/j.semarthrit.2020.04.015.

[302] Roncati L, Bergonzini G, Lusenti B, Nasillo V, Paolini A, Zanelli G, et al. High density of IgG4secreting plasma cells in the fibrotic tissue from a surgically resected tracheal ring impaired by complex subglottic stenosis post-tracheostomy as immune expression of a Th2 response due to severe COVID-19. Ann Hematol 2020;Aug 28:1-2. doi:10.1007/s00277-020-04231-y.

[303] Sousa LP, Pinho V, Teixeira MM. Harnessing inflammation resolving-based therapeutic agents to treat pulmonary viral infections: What can the future offer to COVID-19? Br J Pharmacol 2020;177:3898-904. doi:10.1111/bph.15164.

[304] Afrin LB, Weinstock LB, Molderings GJ. Covid-19 Hyperinflammation and Post-Covid-19 Illness May Be Rooted in Mast Cell Activation Syndrome. Int J Infect Dis 2020;100:327-332. doi:10.1016/j.ijid.2020.09.016.

[305] Kasama I. Stabilizing mast cells by commonly used drugs: a novel therapeutic target to relieve postCOVID syndrome? Drug Discov Ther 2020;14:259-61. doi:10.5582/ddt.2020.03095.

[306] Davido B, Seang S, Tubiana R, de Truchis P. Post-COVID-19 chronic symptoms: a postinfectious entity? Clin Microbiol Infect 2020;26:1448-9. doi:10.1016/j.cmi.2020.07.028.

[307] Chu L, Valencia IJ, Garvert DW, Montoya JG. Onset Patterns and Course of Myalgic Encephalomyelitis/Chronic Fatigue Syndrome. Front Pediatr 2019;7:12. doi:10.3389/fped.2019.00012.

[308] Ellis JE, Missan DS, Shabilla M, Martinez D, Fry SE. Microbial community profiling of peripheral blood in myalgic encephalomyelitis/chronic fatigue syndrome. Hum Microbiome J 2018;9:16-21. doi:10.1016/j.humic.2018.05.003.

[309] Nisenbaum R, Jones JF, Unger ER, Reyes M, Reeves WC. A population-based study of the clinical course of chronic fatigue syndrome. Heal Qual Life Outcomes 2003;1:49. doi:10.1186/1477-7525-1-49.

[310] Rowe PC, Marden CL, Jasion SE, Cranston EM, Flaherty MAK, Kelly KJ. Cow's milk protein intolerance in adolescents and young adults with chronic fatigue syndrome. Acta Paediatr 2016;105:e412-8. doi:10.1111/apa.13476.

[311] Rowe PC, Underhill RA, Friedman KJ, Gurwitt A, Medow MS, Schwartz MS, et al. Myalgic Encephalomyelitis/ Chronic Fatigue Syndrome Diagnosis and Management in Young People: A Primer. Front Pediatr 2017;5:121. doi:10.3389/fped.2017.00121.

[312] Maes M, Leunis J-C. Normalization of leaky gut in chronic fatigue syndrome (CFS) is accompanied by a clinical improvement: effects of age, duration of illness and the translocation of LPS from gram-negative bacteria. Neuroendocr Lett 2008;29:902-10. 
[313] Esposito S, Polinori I, Rigante D. The Gut Microbiota-Host Partnership as a Potential Driver of Kawasaki Syndrome. Front Pediatr 2019;7:124. doi:10.3389/fped.2019.00124.

[314] Nielsen TM, Andersen NH, Torp-Pedersen C, Sogaard P, Kragholm KH. Kawasaki disease, autoimmune disorders, and cancer: a register-based study. Eur J Pediatr 2020. doi:10.1007/s00431-020-03768-4.

[315] Choi BS. The association between asthma and Kawasaki disease. Allergy, Asthma Respir Dis 2019;7:173-8. doi:10.4168/aard.2019.7.4.173.

[316] Hwang CY, Hwang YY, Chen YJ, Chen CC, Lin MW, Chen TJ, et al. Atopic diathesis in patients with kawasaki disease. J Pediatr 2013;163:811-5. doi:10.1016/j.jpeds.2013.03.068.

[317] Rodo X, Curcoll R, Robinson M, Ballester J, Burns JC, Cayan DR, et al. Tropospheric winds from northeastern China carry the etiologic agent of Kawasaki disease from its source to Japan. Proc Natl Acad Sci U S A 2014;111:7952-7. doi:10.1073/pnas.1400380111.

[318] Manlhiot C, Mueller B, O’Shea S, Majeed H, Bernknopf B, Labelle M, et al. Environmental epidemiology of Kawasaki disease: Linking disease etiology, pathogenesis and global distribution. PLoS One 2018;13:e0191087. doi:10.1371/journal.pone.0191087.

[319] Awaya A, Murayama K. Positive Correlation Between Japanese Cedar Pollen Numbers and the Development of Kawasaki Disease. Open Allergy J 2012;5:1-10. doi:10.2174/1874838401205010001.

[320] Obersteiner A, Gilles S, Frank U, Beck I, Haring F, Ernst D, et al. Pollen-associated microbiome correlates with pollution parameters and the allergenicity of pollen. PLoS One 2016;11:e0149545. doi:10.1371/journal.pone.0149545.

[321] Awaya A, Kuroiwa Y. The Relationship between Annual Airborne Pollen Levels and Occurrence of All Cancers, and Lung, Stomach, Colorectal, Pancreatic and Breast Cancers: A Retrospective Study from the National Registry Database of Cancer Incidence in Japan, 1975-2015. Int J Environ Res Public Health 2020;17:3950. doi:10.3390/ijerph17113950.

[322] Wu X, Nethery RC, Sabath BM, Braun D, Dominici F. Exposure to air pollution and COVID-19 mortality in the United States. MedRxiv Prepr 2020. doi:10.1101/2020.04.05.20054502.

[323] Travaglio M, Yu Y, Popovic R, Selley L, Leal NS, Martins LM. Links between air pollution and COVID19 in England. Env Pollut 2020 Oct 19;268(Pt A)115859 2020;268:115859. doi:10.1101/2020.04.05.20054502.

[324] Fattorini D, Regoli F. Role of the chronic air pollution levels in the Covid-19 outbreak risk in Italy. Environ Pollut 2020;264:114732. doi:10.1016/j.envpol.2020.114732.

[325] Santos J, Saperas E, Nogueiras C, Mourelle M, Antolin M, Cadahia A, et al. Release of mast cell mediators into the jejunum by cold pain stress in humans. Gastroenterology 1998;114:640-8. doi:10.1016/s00165085(98)70577-3.

[326] Gao L, Kang M, Zhang MJ, Sailani MR, Kuraji R, Martinez A, et al. Polymicrobial periodontal disease triggers a wide radius of effect and unique virome. Npj Biofilms Microbiomes 2020;6:1-13. doi:10.1038/s41522-020-0120-7.

[327] Stacy A, McNally L, Darch SE, Brown SP, Whiteley M. The biogeography of polymicrobial infection. Nat Rev Microbiol 2015;14:93-105. doi:10.1038/nrmicro.2015.8.

[328] Diakite A, Dubourg G, Dione N, Afouda P, Bellali S, Ngom I, et al. Extensive culturomics of 8 healthy samples enhances metagenomics efficiency. PLoS One 2019;14:e0223543. doi:10.1371/journal.pone.0223543.

[329] Almeida A, Mitchell AL, Boland M, Forster SC, Gloor GB, Tarkowska A, et al. A new genomic blueprint of the human gut microbiota. Nature 2019;568:499-504. doi:10.1038/s41586-019-0965-1. 
[330] Almeida A, Nayfach S, Boland M, Strozzi F, Beracochea M, Shi ZJ, et al. A unified catalog of 204,938 reference genomes from the human gut microbiome. Nat Biotechnol 2020 2020. doi:10.1038/s41587-0200603-3.

[331] Paoli L, Sunagawa S. Space, time and microdiversity: towards a resolution revolution in microbiomics. Environ Microbiol Rep 2020:1758-2229.12897. doi:10.1111/1758-2229.12897.

[332] Piliponsky AM, Acharya M, Shubin NJ. Mast Cells in Viral, Bacterial, and Fungal Infection Immunity. Int J Mol Sci 2019;20:2851. doi:10.3390/ijms20122851.

[333] Secord EA, Kleiner GI, Auci DL, Smith-Norowitz T, Chice S, Finkielstein A, et al. IgE against HIV proteins in clinically healthy children with HIV disease. J Allergy Clin Immunol 1996;98:979-84. doi:10.1016/S0091-6749(96)80015-7.

[334] Karasuyama H, Miyake K, Yoshikawa S, Yamanishi Y. Multifaceted roles of basophils in health and disease. J Allergy Clin Immunol 2018;142:370-80. doi:10.1016/j.jaci.2017.10.042.

[335] Simon HU, Yousefi S, Germic N, Arnold IC, Haczku A, Karaulov A V, et al. The Cellular Functions of Eosinophils: Collegium Internationale Allergologicum (CIA) Update 2020. Int Arch Allergy Immunol 2020;181:11-23. doi:10.1159/000504847.

[336] Dispenza MC. Classification of hypersensitivity reactions. Allergy Asthma Proc 2019;40:470-3. doi:10.2500/aap.2019.40.4274.

[337] Kondo Y, Urisu A. Oral Allergy Syndrome. Allergol Int 2009;58:485-91. doi:10.2332/allergolint.09RAI-0136. 